Open Access

\title{
Neural versus pneumatic control of pressure support in patients with chronic obstructive pulmonary diseases at different levels of positive end expiratory pressure: a physiological study
}

Ling Liu ${ }^{1 \dagger}$, Feiping Xia ${ }^{1 \dagger}$, Yi Yang ${ }^{1}$, Federico Longhini ${ }^{1,2}$, Paolo Navalesi ${ }^{2,3,4}$, Jennifer Beck ${ }^{5,6,8}$, Christer Sinderby, ${ }^{5,7}$ and Haibo Qiu ${ }^{1 *}$

\begin{abstract}
Introduction: Intrinsic positive end-expiratory pressure (PEEPi) is a "threshold" load that must be overcome to trigger conventional pneumatically-controlled pressure support $\left(\mathrm{PS}_{\mathrm{P}}\right.$ ) in chronic obstructive pulmonary disease (COPD). Application of extrinsic PEEP (PEEPe) reduces trigger delays and mechanical inspiratory efforts. Using the diaphragm electrical activity (EAdi), neurally controlled pressure support $\left(\mathrm{PS}_{\mathrm{N}}\right)$ could hypothetically eliminate asynchrony and reduce mechanical inspiratory effort, hence substituting the need for PEEPe. The primary objective of this study was to show that $P S_{N}$ can reduce the need for PEEPe to improve patient-ventilator interaction and to reduce both the "pre-trigger" and "total inspiratory" neural and mechanical efforts in COPD patients with PEEPi. A secondary objective was to evaluate the impact of applying $P S_{N}$ on breathing pattern.
\end{abstract}

Methods: Twelve intubated and mechanically ventilated COPD patients with PEEPi $\geq 5 \mathrm{~cm} \mathrm{H} \mathrm{H}_{2} \mathrm{O}$ underwent comparisons of PSP and PS $S_{N}$ at different levels of PEEPe (at $0 \%, 40 \%, 80 \%$, and $120 \%$ of static PEEPi, for 12 minutes at each level on average), at matching peak airway pressure. We measured flow, airway pressure, esophageal pressure, and EAdi, and analyzed neural and mechanical efforts for triggering and total inspiration. Patient-ventilator interaction was analyzed with the NeuroSync index.

Results: Mean airway pressure and PEEPe were comparable for $P S_{P}$ and $P S_{N}$ at same target levels. During $P S_{P}$, the NeuroSync index was $29 \%$ at zero PEEPe and improved to $21 \%$ at optimal PEEPe $(P<0.05)$. During $P S_{N}$, the NeuroSync index was lower $(<7 \%, P<0.05)$ regardless of PEEPe. Both pre-trigger $(P<0.05)$ and total inspiratory mechanical efforts $(P<0.05)$ were consistently higher during $P S_{P}$ compared to $P S_{N}$ at same PEEPe. The change in total mechanical efforts between $\mathrm{PS}_{\mathrm{P}}$ at $\mathrm{PEEPe_{0 \% }}$ and $\mathrm{PS}_{\mathrm{N}}$ at $\mathrm{PEEPe_{0 }}$ was not different from the change between $\mathrm{PS}_{\mathrm{P}}$ at PEEPe $e_{0 \%}$ and $P S_{P}$ at $P E E P e_{80 \%}$.

Conclusion: $\mathrm{PS}_{\mathrm{N}}$ abolishes the need for PEEPe in COPD patients, improves patient-ventilator interaction, and reduces the inspiratory mechanical effort to breathe.

Trial registration: Clinicaltrials.gov NCT02114567. Registered 04 November 2013.

\footnotetext{
*Correspondence: haiboq2000@126.com

${ }^{\dagger}$ Equal contributors

'Department of Critical Care Medicine, Nanjing Zhongda Hospital, Southeast University, School of Medicine, 87 Dingjiagiao Street, Nanjing 210009, China Full list of author information is available at the end of the article
}

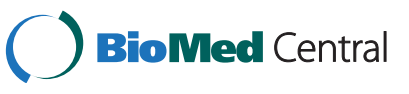

(c) 2015 Liu et al. This is an Open Access article distributed under the terms of the Creative Commons Attribution License (http://creativecommons.org/licenses/by/4.0), which permits unrestricted use, distribution, and reproduction in any medium, provided the original work is properly credited. The Creative Commons Public Domain Dedication waiver (http:// creativecommons.org/publicdomain/zero/1.0/) applies to the data made available in this article, unless otherwise stated. 


\section{Introduction}

Intrinsic positive end-expiratory pressure (PEEPi) refers to the increase in the end-expiratory elastic recoil pressure associated with an increase in lung volume above resting lung volume at end expiration consequent to dynamic hyperinflation. PEEPi impairs patient-ventilator interaction and efficiency of ventilatory assistance, increases inspiratory effort, causes dyspnea, and alters hemodynamics $[1,2]$.

In spontaneously breathing patients on conventional ventilatory assistance, PEEPi typically reveals itself as a delayed onset of assistance relative to the onset of neural inspiratory effort, where if ventilatory assistance is triggered on pressure, flow, or volume (i.e., pneumatic trigger), the PEEPi-induced threshold load must be overcome to initiate assistance [3]. Work in patients with chronic obstructive pulmonary disease (COPD) has demonstrated that application of external PEEP (PEEPe) can reduce the mechanical inspiratory effort [3-5].

In COPD patients receiving pressure support (PS) with pneumatic triggering and cycling-off, $\left(\mathrm{PS}_{\mathrm{P}}\right)$, the increased airway resistance prolongs the time constant and delays the cycling-off of ventilator support. Studies suggest a higher than conventional percentage of peak flow is required to adequately terminate assist; inappropriate settings for the cycling-off criteria are known to worsen dynamic hyperinflation and increase PEEPi [6, 7].

The effects of neural cycling-off of assistance in patients with COPD and PEEPi have not been evaluated during PS ventilation. Controlling ventilatory assistance by the diaphragm electrical activity (EAdi) - a neural signal - successfully improves patient-ventilator interaction during neurally adjusted ventilatory assistance (NAVA) compared to $\mathrm{PS}_{\mathrm{P}}[8,9]$. A recent study has shown that the use of NAVA also leads to a decrease in the effort to trigger the ventilator, when compared to $\left(\mathrm{PS}_{\mathrm{P}}\right)$ [10]. These previous studies, however, compared a pressuretargeted mode $\left(\mathrm{PS}_{\mathrm{P}}\right)$ to a proportional mode (NAVA). Therefore, in the present study, we used neurally controlled PS $\left(\mathrm{PS}_{\mathrm{N}}\right)$, where the EAdi was used to initiate and terminate the breath, but with a targeted, fixed pressure. The primary objective was to show that $\mathrm{PS}_{\mathrm{N}}$ can reduce the need for PEEPe to improve patient-ventilator interaction and to reduce both the pre-trigger and total inspiratory neural and mechanical efforts in COPD patients with PEEPi. A secondary objective was to evaluate the impact of applying $\mathrm{PS}_{\mathrm{N}}$ on breathing pattern.

\section{Methods}

The study was conducted in a 30-bed general intensive care unit (ICU) of a teaching hospital affiliated with Southeast University in China. The protocol was approved by Institutional Ethics Committee of Zhongda hospital (Approval Number: 2010ZDLL018.0), and informed consent was obtained from the patients or next of kin. The trial was registered at clinicaltrials.gov (NCT02114567).

\section{Patients}

Twelve adult intubated and mechanically ventilated patients with early COPD and acute respiratory failure due to pneumonia were studied. COPD was defined as the patient having chronic cough, sputum or progressive dyspnea, and forced vital capacity rate of one second $\left(\mathrm{FEV}_{1} / \mathrm{FVC}\right)<0.7$ after bronchodilation. Acute respiratory failure was defined as oxygenation index $\left(\mathrm{PaO}_{2} /\right.$ $\left.\mathrm{FiO}_{2}\right)<300 \mathrm{mmHg}$ with or without elevated arterial carbon dioxide tension $\left(\mathrm{PaCO}_{2}\right)$.

The inclusion criteria were: (1) static PEEPi $\geq 5 \mathrm{~cm}$ $\mathrm{H}_{2} \mathrm{O}$ (see below); (2) hemodynamic stability (heart rate $<140$ beats/minute, no vasopressors required, or $<5 \mu \mathrm{g} /$ $\mathrm{kg} / \mathrm{min}$ dopamine); (3) no sedation or minimal analgesia with low dose of morphine $(<3 \mathrm{mg} / \mathrm{h}$, by continuous intravenous infusion); (4) breathing spontaneously but in need of partial ventilatory assistance, and (5) awake and able to positively cooperate, defined as the ability to follow an instruction (e.g., open their eyes, raise thumbs up, move limbs).

The exclusion criteria were: (1) tracheostomy; (2) treatment abandonment; (3) history of esophageal varices; (4) gastroesophageal surgery in the previous 12 months or gastroesophageal bleeding in the previous 30 days; (5) coagulation disorders (international normalized ratio $>1.5$ and activated partial thromboplastin time $>44 \mathrm{~s}$ ); (6) history of acute central or peripheral nervous system disorder or neuromuscular disease, and (7) lack of informed consent.

\section{Measurements}

After obtaining consent, enrolled patients were switched to a Servo-i ventilator (Maquet, Solna, Stockholm, Sweden). A 16-F nasogastric feeding tube (NeuroVent Research Inc; Toronto, ON, Canada) with electrodes measuring EAdi and balloons measuring esophageal (Pes) and gastric (Pga) pressures was inserted through the nose and secured after confirming positioning according to guidelines for NAVA catheter positioning (Maquet, Solna, Stockholm, Sweden). Flow and airway pressure (Paw) were acquired from the Servo-i ventilator whereas Pes and Pga were obtained via pressure transducers; all signals were digitized at $100 \mathrm{~Hz}$ and stored for offline analysis (NeuroVent Research Inc.; Toronto, ON, Canada). Mean arterial pressure (MAP) was measured with a blood pressure cuff (Philips G60).

\section{$\mathrm{PS}_{\mathrm{P}}$ and $\mathrm{PS}_{\mathrm{N}}$}

\section{Pneumatically controlled PS}

Conventional pneumatically controlled PS ( $\mathrm{PS}_{\mathrm{P}}$ ) was used with the ventilator in the pressure support mode and was pneumatically triggered (flow-trigger $1 \mathrm{~L} / \mathrm{min}$ ) and cycled 
off ( $30 \%$ of peak inspiratory flow). The rate of rise in pressure was set to $0.05 \mathrm{~s}$ in all patients.

\section{Neurally controlled PS}

Neurally controlled PS $\left(\mathrm{PS}_{\mathrm{N}}\right)$ was used with the ventilator in the NAVA mode, however, the NAVA level was set to maximum (NAVA level $15 \mathrm{cmH}_{2} \mathrm{O} / \mu \mathrm{V}$ ) with upper pressure limits adjusted to achieve the targeted PS above PEEPe (same as $\mathrm{PS}_{\mathrm{P}}$ ). $\mathrm{PS}_{\mathrm{N}}$ was neurally triggered (EAdi trigger $=0.5 \mu \mathrm{V})$ and cycled off (70\% of peak EAdi).

\section{Study protocol}

\section{Determination of static PEEPi}

Patients were initially on volume control ventilation (VCV) at zero PEEPe, tidal volume $\left(\mathrm{V}_{\mathrm{T}}\right) 6 \mathrm{~mL} / \mathrm{kg}$ predicted body-weight (PBW), and inspiratory flow of $40 \mathrm{~L} /$ $\mathrm{min}$, and mandatory breathing frequency (Bf) matching that observed during $\mathrm{PS}_{\mathrm{P}}$ before sedation. To suppress the spontaneous drive to breathe (abolish EAdi), patients received continuous intravenous (IV) sedation by Propofol up to the dose of $2 \mathrm{mg} / \mathrm{kg} / \mathrm{h}$. If at this propofol dose the respiratory drive was not totally suppressed, Remifentanil was also infused at the dose of $6-15 \mu \mathrm{g} / \mathrm{kg} / \mathrm{h}$ just before the measurement of compliance, resistance and static PEEPi. Static PEEPi was assessed during VCV at PEEPe of zero using the end-expiratory airway occlusion method [2]. PEEPe levels of $0 \%, 40 \%, 80 \%$, and $120 \%$ of static PEEPi were then calculated and noted (subsequently referred to as $\mathrm{PEEPe}_{0 \%}, \mathrm{PEEPe}_{40 \%}, \mathrm{PEEPe}_{80 \%}$, and $\mathrm{PEEPe}_{120 \%}$ ). PEEPe was increased to determine the presence of expiratory flow limitation (EFL) [2].

\section{Spontaneous breathing and return to PS at different levels of PEEPe}

Sedation was discontinued and as spontaneous breathing and EAdi recovered, patients were returned to $\mathrm{PS}_{\mathrm{P}}$ and adjusted to target $6 \mathrm{ml} / \mathrm{kg}$ (of PBW) and PEEPe of 5 $\mathrm{cmH}_{2} \mathrm{O}$ until a Ramsay score of 2-3 was obtained. This was followed by eight different ventilation periods: $\mathrm{PS}_{\mathrm{P}}$ and $\mathrm{PS}_{\mathrm{N}}$ at $\mathrm{PEEPe}_{0 \%}, \mathrm{PEEPe}_{40 \%}, \mathrm{PEEPe}_{80 \%}$, and PEEPe $\mathrm{P}_{120 \%}$. First $\mathrm{PS}_{\mathrm{P}}$ was applied targeting $6 \mathrm{ml} / \mathrm{kg}$ PBW with PEEPe levels randomized to be applied with either ascending or descending order. This was then repeated during $\mathrm{PS}_{\mathrm{N}}$ with same PEEPe levels (as used with $\mathrm{PS}_{\mathrm{P}}$ ) randomized to either ascending or descending order (independent of the order used during $\mathrm{PS}_{\mathrm{P}}$ ). Assistance pressure above PEEPe was obtained by adjusting the upper pressure limit to the same assistance pressure (above PEEPe) that was observed for the corresponding PEEPe during the $\mathrm{PS}_{\mathrm{P}}$ period. The average duration per PEEPe level was $12( \pm 1 \mathrm{SD})$ minutes. Arterial blood gases were measured at the end of each PEEPe level. Inspired fraction of oxygen $\left(\mathrm{FiO}_{2}\right)$ was set similar to that at inclusion (Table 1) and not altered throughout the study.

\section{Data analysis}

Parameters during volume control ventilation (and no spontaneous breathing)

Compliance was calculated from the formula:

Tidal volume/(Plateau pressure-total PEEP).

Resistance was calculated from the formula:

Resistance $=($ Peak pressure-Plateau pressure $) /$ Flow .

EFL was determined from peak airway pressure during increase of PEEPe [2].

\section{Respiratory parameters during spontaneous breathing on $P S_{P}$ or $P S_{N}$}

The last 3 minutes of each condition were analyzed for the EAdi-derived, ventilator, and Pes-derived variables.

EAdi-derived variables Neural inspiratory time $\left(\mathrm{Ti}_{\mathrm{N}}\right)$ was calculated between the onset of EAdi and the return to $70 \%$ of peak EAdi. Neural expiratory time $\left(\mathrm{Te}_{\mathrm{N}}\right)$ was calculated as the time between the return to $70 \%$ of peak EAdi and the onset of the next EAdi. We also calculated the neural duty cycle $\left(\mathrm{Ti}_{\mathrm{N}} / \mathrm{Tt}_{\mathrm{N}}\right.$, where $\left.\mathrm{Tt}_{\mathrm{N}}=\mathrm{Ti}_{\mathrm{N}}+\mathrm{Te}_{\mathrm{N}}\right)$, and neural breathing frequency $\left(\mathrm{Bf}_{\mathrm{N}}=60 / \mathrm{Tt}_{\mathrm{N}}\right)$. The peak inspiratory EAdi (ÊAdi) was calculated for the pre-trigger

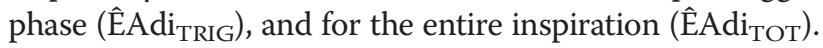

Ventilator variables PEEPe was measured as mean airway pressure in the expiratory state. $\mathrm{V}_{\mathrm{T}}$ was obtained by flow integration. Mean airway pressure ( $\bar{P} a w)$ was calculated during neural inspiration. Pneumatic inspiratory and expiratory times $\left(\mathrm{Ti}_{\mathrm{P}}\right.$ and $\left.\mathrm{Te}_{\mathrm{P}}\right)$ were calculated from the airway pressure signal.

Pes-derived variables The mean inspiratory change in Pes was calculated from onset of each inspiration (based on EAdi) for both the pre-trigger phase $\left(\Delta \overline{\mathrm{P}} \mathrm{es}_{\mathrm{TRIG}}\right)$, as well as the total inspiration (pre-trigger effort included, $\left.\Delta \overline{\mathrm{P}} \mathrm{es}_{\mathrm{TOT}}\right)$. Transpulmonary pressure $\left(\mathrm{P}_{\mathrm{L}}\right)$ was calculated as Paw-Pes, and is presented for the total inspiration $\mathrm{P}_{\mathrm{L}}\left(\Delta \overline{\mathrm{P}}_{\mathrm{LTOT}}\right)$. Pre-trigger inspiratory pressure time product per minute was calculated for Pes (PTPes ${ }_{\text {TRIG }}$ ) as $\left(\Delta \bar{P}_{\text {TRIG }} \times \mathrm{T}_{\text {TRIG }} \times \mathrm{Bf}_{\mathrm{N}}\right)$, and for the total inspiration $\left(\mathrm{PTPes}_{\mathrm{TOT}}\right)$ as $\left(\Delta \overline{\mathrm{P}} \mathrm{es}_{\mathrm{TOT}} \times \mathrm{Ti}_{\mathrm{N}} \times \mathrm{Bf}_{\mathrm{N}}\right)$. Neuromechanical efficiency (NME) was calculated for total inspiration as $\Delta \overline{\mathrm{P} e s} / \hat{\mathrm{E} A d i}$.

\section{Analysis of patient-ventilator interaction}

EAdi-to-trigger time difference in $\mathrm{ms}\left(\mathrm{T}_{\mathrm{TRIG}}\right)$ was calculated between onset of EAdi and early initial rise in Paw. Cycling-off timing-difference in milliseconds ( $\left.\mathrm{T}_{\mathrm{CYC}-\mathrm{OFF}}\right)$ was calculated between time points for early decrease in Paw and $30 \%$ decline from EAdi peak.

Patient-ventilator interaction was evaluated by the NeuroSync Index, comparing Paw and EAdi waveforms 
Table 1 Patient demographics

\begin{tabular}{|c|c|c|c|c|c|c|c|c|c|}
\hline \multirow[t]{2}{*}{ Patient } & \multirow[t]{2}{*}{ Gender } & \multirow[t]{2}{*}{ Diagnosis } & \multirow[t]{2}{*}{ APACHE ॥ } & \multirow[t]{2}{*}{$\begin{array}{l}\text { Days } \\
\text { on MV }\end{array}$} & \multirow{2}{*}{$\begin{array}{l}\mathrm{FiO}_{2} \\
\%\end{array}$} & \multirow{2}{*}{$\begin{array}{l}\mathrm{C}_{\mathrm{RS}} \\
\mathrm{ml} / \mathrm{cm} \mathrm{H}_{2} \mathrm{O}\end{array}$} & \multirow{2}{*}{$\begin{array}{l}\mathrm{R}_{\mathrm{RS}} \\
\mathrm{cm} \mathrm{H} \mathrm{H}_{2} \mathrm{O} / \mathrm{l} / \mathrm{s}\end{array}$} & \multirow{2}{*}{$\begin{array}{l}\text { PEEPi }_{\text {STAT }} \\
\mathrm{cm} \mathrm{H}_{2} \mathrm{O}\end{array}$} & \multirow{2}{*}{$\begin{array}{l}\text { FEV1 } \\
\text { \% predicted }\end{array}$} \\
\hline & & & & & & & & & \\
\hline 1 & M & $\begin{array}{l}\text { AECOPD, pneumonia, type } 2 \text { respiratory failure, } \\
\text { pulmonary encephalopathy }\end{array}$ & 32 & 5 & 40 & 33 & 19 & 6 & 56 \\
\hline 2 & M & AECOPD, pneumonia, type 2 respiratory failure & 33 & 6 & 40 & 43 & 15 & 8 & 48 \\
\hline 3 & M & $\begin{array}{l}\text { AECOPD, pneumonia, type } 2 \text { respiratory failure, } \\
\text { septic shock }\end{array}$ & 22 & 4 & 40 & 40 & 16 & 6 & 62 \\
\hline 4 & M & $\begin{array}{l}\text { AECOPD, pneumonia, type } 2 \text { respiratory failure, } \\
\text { pulmonary encephalopathy }\end{array}$ & 34 & 4 & 40 & 42 & 18 & 5 & 41 \\
\hline 5 & M & $\begin{array}{l}\text { AECOPD, pneumonia, type } 2 \text { respiratory failure, } \\
\text { pulmonary encephalopathy }\end{array}$ & 35 & 3 & 40 & 30 & 16 & 5 & 58 \\
\hline 6 & M & $\begin{array}{l}\text { AECOPD, pneumonia, type } 2 \text { respiratory failure, } \\
\text { pulmonary encephalopathy }\end{array}$ & 33 & 2 & 40 & 26 & 16 & 6 & 55 \\
\hline 7 & $M$ & $\begin{array}{l}\text { AECOPD, pneumonia, type } 2 \text { respiratory failure, } \\
\text { pulmonary encephalopathy }\end{array}$ & 31 & 5 & 40 & 27 & 21 & 5 & 38 \\
\hline 8 & F & $\begin{array}{l}\text { AECOPD, pneumonia, type } 2 \text { respiratory failure, } \\
\text { pulmonary encephalopathy }\end{array}$ & 32 & 5 & 40 & 31 & 27 & 5 & 47 \\
\hline 9 & M & $\begin{array}{l}\text { AECOPD, pneumonia, type } 2 \text { respiratory failure, } \\
\text { septic shock }\end{array}$ & 42 & 8 & 40 & 42 & 23 & 5 & 46 \\
\hline 10 & $M$ & $\begin{array}{l}\text { AECOPD, pneumonia, type } 2 \text { respiratory failure, } \\
\text { pulmonary encephalopathy }\end{array}$ & 30 & 1 & 40 & 40 & 26 & 5 & 50 \\
\hline 11 & $\mathrm{~F}$ & $\begin{array}{l}\text { AECOPD, pneumonia, type } 2 \text { respiratory failure, } \\
\text { pulmonary encephalopathy }\end{array}$ & 31 & 2 & 40 & 23 & 24 & 6 & 37 \\
\hline 12 & $\mathrm{~F}$ & $\begin{array}{l}\text { AECOPD, pneumonia, type } 2 \text { respiratory failure, } \\
\text { pulmonary encephalopathy }\end{array}$ & 34 & 1 & 50 & 20 & 17 & 8 & 44 \\
\hline Mean & & & 32.4 & 3.8 & 40.8 & 33.1 & 19.8 & 5.8 & 48.5 \\
\hline SD & & & 4.5 & 2.1 & 2.9 & 8.1 & 4.2 & 1.1 & 8.0 \\
\hline
\end{tabular}

APACHE acute physiology and chronic health evaluation, $A E C O P D$ acute exacerbation of chronic obstructive pulmonary disease, $M V$ mechanical ventilation, $C_{R S}$ compliance of respiratory system, $R_{R S}$ resistance of respiratory system, PEEPI ${ }_{S T A T}$ static intrinsic positive end expiratory pressure, FEV 1 forced expiratory volume in one second

with automated computer algorithms [11] and quantifying the error between them. Briefly, trigger and cyclingoff errors were classified as either too early (negative values) or too late (positive values). Early and late triggering was defined as assistance starting before or after the onset of EAdi. Early and late cycling-off was defined as assistance starting before or after the return of EAdi to $70 \%$ of its peak. Early trigger and cycling-off errors were normalized to the associated neural expiratory or inspiratory periods, respectively and presented in percent with a negative sign. Late trigger and cycling-off errors were normalized to related neural inspiratory or expiratory periods, respectively, and presented in percent with a positive sign. EAdi without associated assistance (ineffective effort) was defined as entire neural breathing cycles taking place without triggering assistance, and was assigned $100 \%$ error. Assistance without associated EAdi (auto triggering) was defined as entire assistance cycles taking place without associated EAdi, and was assigned $100 \%$ error. The NeuroSync index was calculated by averaging the errors for all events, the higher the NeuroSync index, the greater the error between EAdi and Paw.

\section{Statistics}

Statistical analysis was performed with Sigma-Stat 3.5 (Jandel Scientific, California, USA). (Jandel Scientific, California, USA) Three types of comparisons were made: (i) within a mode, the impact of increasing PEEPe, (ii) at a given PEEPe, the impact of $\mathrm{PS}_{\mathrm{P}}$ versus $\mathrm{PS}_{\mathrm{N}}$, (iii) $\mathrm{PS}_{\mathrm{N}}$ at $\mathrm{PEEPe}_{0 \%}$ versus $\mathrm{PS}_{\mathrm{P}}$ at $\mathrm{PEEPe}_{80 \%}$ (considered to be optimal PEEP). Due to non-normally distributed data, we opted for within-subject comparison of all eight conditions using one-way repeated measures analysis of variance (ANOVA) on ranks and Student-Newman-Keuls test for post hoc analysis of multiple comparisons. Significant difference was defined as $P<0.05$. Power calculation suggested that a reduction of inspiratory effort by $50 \%$ required 12 patients for a power of 1.0 with alpha of 0.05 . To test if mechanical respiratory efforts were reduced similarly during $\mathrm{PS}_{\mathrm{N}}$ without PEEPe and during $\mathrm{PS}_{\mathrm{P}}$ with optimal PEEPe linear regression and Pearson productmoment correlation was used.

\section{Results}

A total of 17 patients were screened; 5 did not meet the inclusion criteria of $5 \mathrm{~cm} \mathrm{H}_{2} \mathrm{O}$ static PEEPi. Characteristics 
of the 12 enrolled patients are summarized in Table 1 . All had acute exacerbation of COPD and type 2 respiratory failure. Six patients showed evidence of EFL. The mean age was $78.8(\mathrm{SD} \pm 8.6)$ and body mass index (BMI) was 22.7 (SD \pm 4.2). The last available forced expiratory volume in one second $\left(\mathrm{FEV}_{1}\right)$ was $48.5 \%(\mathrm{SD} \pm 8.0 \%)$ predicted. The mean respiratory rate setting during $\mathrm{VCV}$ was 15 (SD \pm 2 ) breaths per minute.

Table 2 provides the ventilation parameters for the group, at different PEEPe levels, for $\mathrm{PS}_{\mathrm{P}}$ and $\mathrm{PS}_{\mathrm{N}}$. As per protocol design, $\bar{P}$ aw and PEEPe were matched for $\mathrm{PS}_{\mathrm{P}}$ and $\mathrm{PS}_{\mathrm{N}}$ at the same targeted levels (Table 2). The median time to peak pressure was $0.22 \mathrm{~s}\left(0.21-0.23,25^{\text {th }}-75^{\text {th }}\right.$ percentile) in $\mathrm{PS}_{\mathrm{B}}$ and was slightly shorter in $\mathrm{PS}_{\mathrm{N}}(0.17 \mathrm{~s}$, $0.15-0.22)$, the difference being $0.05 \mathrm{~s}(P=0.04)$. Figure 1 shows an example of the time-tracings of flow, volume,
Paw, Pes, Pga, and EAdi during $\mathrm{PS}_{\mathrm{P}}$ at $\mathrm{PEEPe}_{0 \%}$ (top) and $\mathrm{PEEPe}_{80 \%}$ (middle) and during $\mathrm{PS}_{\mathrm{N}}$ at $\mathrm{PEEPe}_{0 \%}$ (bottom) for one individual patient.

\section{Patient-ventilator interaction}

It can also be seen by the time tracings in Fig. 1, that patient-ventilator interaction was worse in $\mathrm{PS}_{\mathrm{P}}$ than $\mathrm{PS}_{\mathrm{N}}$. For the group (Table 3 ), both triggering $\left(\mathrm{T}_{\mathrm{TRIG}}\right)$ and cycling-off ( $\left.\mathrm{T}_{\mathrm{CYC}-\mathrm{OFF}}\right)$ were consistently delayed during $\mathrm{PS}_{\mathrm{P}}$ with delays at $\mathrm{PEEPe}_{80 \%}$ being $114 \mathrm{~ms}$ (trigger) and $118 \mathrm{~ms}$ (cycling-off) longer than during $\mathrm{PS}_{\mathrm{N}}$ at $\mathrm{PEEPe}_{0 \%}$. Increasing from $\mathrm{PEEPe}_{0 \%}$ to $\mathrm{PEEPe}_{80 \%}$ during $\mathrm{PS}_{\mathrm{P}}$ reduced the trigger delay by $93 \mathrm{~ms}(P<0.05)$ and delayed cyclingoff by $54 \mathrm{~ms}$. Timing of triggering and cycling-off was not affected by PEEPe during $\mathrm{PS}_{\mathrm{N}}$.

Table 2 Ventilation parameters, arterial blood gases, and mean arterial pressure at different PEEPe for $\mathrm{PS}_{\mathrm{N}}$ and $P S_{\mathrm{P}}$

\begin{tabular}{|c|c|c|c|c|c|c|}
\hline Parameter & Mode & $\mathrm{PEEPe}_{0 \%}$ & $\mathrm{PEEPe}_{40 \%}$ & $\mathrm{PEEPe}_{80 \%}$ & $\mathrm{PEEPe}_{120 \%}$ & $P^{*}$ \\
\hline \multirow[t]{2}{*}{$\overline{\bar{P} a w ~}\left(\mathrm{~cm} \mathrm{H}_{2} \mathrm{O}\right)$} & $P S_{P}$ & $10.9(10.3,11.3)$ & $12.9(12.3,13.3)^{\mathrm{a}}$ & $15.0(14.8,16.3)^{\mathrm{ab}}$ & $17.4(16.8,18.3)^{\mathrm{abc}}$ & $<0.001$ \\
\hline & $P S_{N}$ & $11.4(10.8,11.6)^{x}$ & $13.1(12.1,13.3)^{\mathrm{a}}$ & $15.2(14.4,16.4)^{\mathrm{ab}}$ & $17.5(16.9,18.6)^{\mathrm{abc}}$ & \\
\hline \multirow[t]{2}{*}{ PEEPe $\left(\mathrm{cm} \mathrm{H}_{2} \mathrm{O}\right)$} & $P S_{p}$ & $0.6(0.4,1.0)^{z}$ & $2.3(2.2,2.5)^{a z}$ & $4.7(4.2,5.4)^{\mathrm{ab}}$ & $7.1(6.5,7.5)^{\mathrm{abc}}$ & $<0.001$ \\
\hline & $P S_{N}$ & $1.0(0.5,1.2)^{x}$ & $2.5(2.3,3.0)^{\mathrm{a}}$ & $4.7(4.4,5.4)^{a b}$ & $7.0(6.6,7.5)^{\mathrm{abc}}$ & \\
\hline \multirow[t]{2}{*}{$\mathrm{V}_{\mathrm{T}}(\mathrm{ml} / \mathrm{kg})$} & $P S_{p}$ & $5.4(4.2,6.7)^{z}$ & $5.8(4.9,6.8)^{z}$ & $5.9(5.0,6.6)^{\mathrm{abz}}$ & $5.5(5.2,7.0)^{a b}$ & $<0.001$ \\
\hline & $P S_{N}$ & $4.6(4.3,5.8)^{x}$ & $5.0(4.4,5.9)^{\mathrm{a}}$ & $4.9(4.6,6.7)^{\mathrm{ab}}$ & $5.0(4.6,7.1)^{\mathrm{abc}}$ & \\
\hline \multirow[t]{2}{*}{$\mathrm{Bf}_{\mathrm{N}}$ (breaths/min) } & $P S_{p}$ & $20.2(17.7,29.3)^{z}$ & $20.5(17.6,28.9)^{z}$ & $21.5(17.2,26.9)^{z}$ & $20.9(17.9,30.3)$ & 0.003 \\
\hline & $P S_{N}$ & $26.4(17.3,30.7)^{x}$ & $24.4(17.2,33.2)$ & $22.1(18.1,31.5)^{\mathrm{ab}}$ & $20.5(16.0,29.6)^{\mathrm{ab}}$ & \\
\hline \multirow[t]{2}{*}{$V_{E}(1 / m i n)$} & $P S_{P}$ & $6.05(5.25,8.13)^{z}$ & $6.54(5.47,8.91)^{a}$ & $7.05(5.67,9.02)^{a}$ & $7.07(5.70,11.62)^{a}$ & $<0.001$ \\
\hline & $P S_{N}$ & $6.43(5.31,9.54)^{x}$ & $6.92(5.53,9.98)^{a}$ & $7.14(5.50,9.20)^{a}$ & $7.79(5.74,9.66)^{a}$ & \\
\hline \multirow[t]{2}{*}{$\mathrm{V}_{T} / T \mathrm{i}_{\mathrm{p}}(\mathrm{ml} / \mathrm{s})$} & $P S_{P}$ & $424(390,446)^{z}$ & $429(389,472)$ & $436(386,458)$ & $438(396,466)$ & 0.013 \\
\hline & $P S_{N}$ & $414(302,491)^{x}$ & $443(334,508)^{a}$ & $452(338,526)^{a}$ & $479(361,513)^{a}$ & \\
\hline \multirow[t]{2}{*}{$\operatorname{Ti}_{N}(s)$} & $P S_{P}$ & $0.90(0.72,1.03)$ & $0.90(0.74,0.94)$ & $0.84(0.73,0.98)$ & $0.87(0.69,0.93)$ & NS \\
\hline & $P S_{N}$ & $0.84(0.71,0.96)$ & $0.77(0.71,0.86)$ & $0.81(0.74,0.86)$ & $0.84(0.73,0.95)$ & \\
\hline \multirow[t]{2}{*}{$T e_{N}(s)$} & $P S_{P}$ & $2.12(1.43,2.60)^{z}$ & $2.22(1.45,2.93)$ & $2.17(1.58,3.14)^{z}$ & $2.13(1.53,2.58)$ & 0.050 \\
\hline & $P S_{N}$ & $1.76(1.16,2.66)^{x}$ & $2.09(1.20,2.77)^{a}$ & $2.02(1.24,2.59)^{a}$ & $2.14(1.33,2.92)^{a}$ & \\
\hline \multirow[t]{2}{*}{$\mathrm{Ti}_{N} / \mathrm{Tt}_{\mathrm{N}}(\%)$} & $P S_{P}$ & $29.6(27.5,36.5)$ & $28.7(24.5,39.0)$ & $27.1(23.4,36.3)$ & $26.1(23.0,36.7)$ & NS \\
\hline & $P S_{N}$ & $31.4(25.6,37.8)$ & $29.4(23.9,38.5)$ & $29.7(24.6,38.3)$ & $30.6(22.5,36.8)$ & \\
\hline \multirow[t]{2}{*}{$\mathrm{pH}$} & $P S_{p}$ & $7.36(7.33,7.41)$ & $7.38(7.36,7.41)^{\mathrm{a}}$ & $7.39(7.34,7.44)^{\mathrm{a}}$ & $7.39(7.33,7.42)^{a}$ & 0.009 \\
\hline & $P S_{N}$ & $7.37(7.33,7.40)^{x}$ & $7.39(7.34,7.42)^{a}$ & $7.38(7.32,7.45)^{a}$ & $7.38(7.35,7.42)^{a}$ & \\
\hline \multirow[t]{2}{*}{$\mathrm{PaCO}_{2}(\mathrm{~mm} \mathrm{Hg})$} & $P S_{P}$ & $37.9(32.0,48.6)$ & $35.9(31.2,46.1)$ & $36.3(32.1,46.8)$ & $33.5(32.9,43.3)$ & NS \\
\hline & $P S_{N}$ & $40.4(29.8,47.5)$ & $34.2(31.2,42.1)$ & $35.4(32.8,41.8)$ & $36.5(30.7,41.9)$ & \\
\hline \multirow[t]{2}{*}{$\mathrm{PaO}_{2}(\mathrm{~mm} \mathrm{Hg})$} & $P S_{P}$ & $84.0(79.9,113.9)$ & $94.8(84.9,116.7)$ & $98.7(90.0,124.3)$ & $103.9(84.0,117.2)$ & NS \\
\hline & $P S_{N}$ & $89.7(83.5,122.9)$ & $106.6(81.2,124.1)$ & $99.4(91.0,123.9)$ & $109.0(95.0,125.8)$ & \\
\hline \multirow[t]{2}{*}{ MAP (mm Hg) } & $P S_{P}$ & $89.0(76.0,92.7)$ & $88.0(77.0,92.7)$ & $86.7(77.7,91.7)$ & $89.3(79.0,91.3)$ & NS \\
\hline & $P S_{N}$ & $88.3(75.7,91.3)$ & $88.0(75.3,90.4)$ & $88.7(78.3,91.0)$ & $86.7(80.3,92.0)$ & \\
\hline
\end{tabular}

Values are presented as median (25-75\% interquartile range). ${ }^{*} P$ values for one-way repeated measures analysis of variance on ranks for the eight conditions: within the same mode: ${ }^{\mathrm{a}} P<0.05$ compared to $P E E P \mathrm{P}_{0 \%} ;{ }^{\mathrm{b}} P<0.05$ compared to $P E E P e_{40 \%} ;{ }^{\mathrm{C}} P<0.05$ compared to $P E E P \mathrm{e}_{80 \%}$. Between modes: ${ }^{\mathrm{Z}} P<0.05$ compared to $\mathrm{PS}_{\mathrm{N}}$ at same PEEPe. Comparison of $\mathrm{PS}_{\mathrm{N}}$ zero PEEP to $\mathrm{PS}_{\mathrm{P}}$ optimal PEEP: ${ }^{{ } P}<0.05 \mathrm{PEEPe}_{0 \%}$ at $\mathrm{PS}_{\mathrm{N}} \mathrm{Vs}$. $\mathrm{PEEPe}_{80 \%}$ at $P \mathrm{PS}_{\mathrm{P}}$. $P S_{\mathrm{P}}$ pneumatically triggered and cycled-off pressure support, $P S_{N}$ neurally triggered and cycled-off pressure support ventilation, $\bar{P} a w$ mean airway pressure (including PEEPe), PEEPe extrinsic PEEP, $V_{T}$ tidal volume, $V_{E}$ minute ventilation, $T i_{N}$ neural inspiratory time, $T e_{N}$ neural expiratory time, $T i / T$ tot $T_{N}$ neural duty cycle, $B f_{N}$ neural breathing frequency, $P E E P I_{S T A T}$ static intrinsic positive end-expiratory pressure, MAP mean arterial pressure, NS not significant 


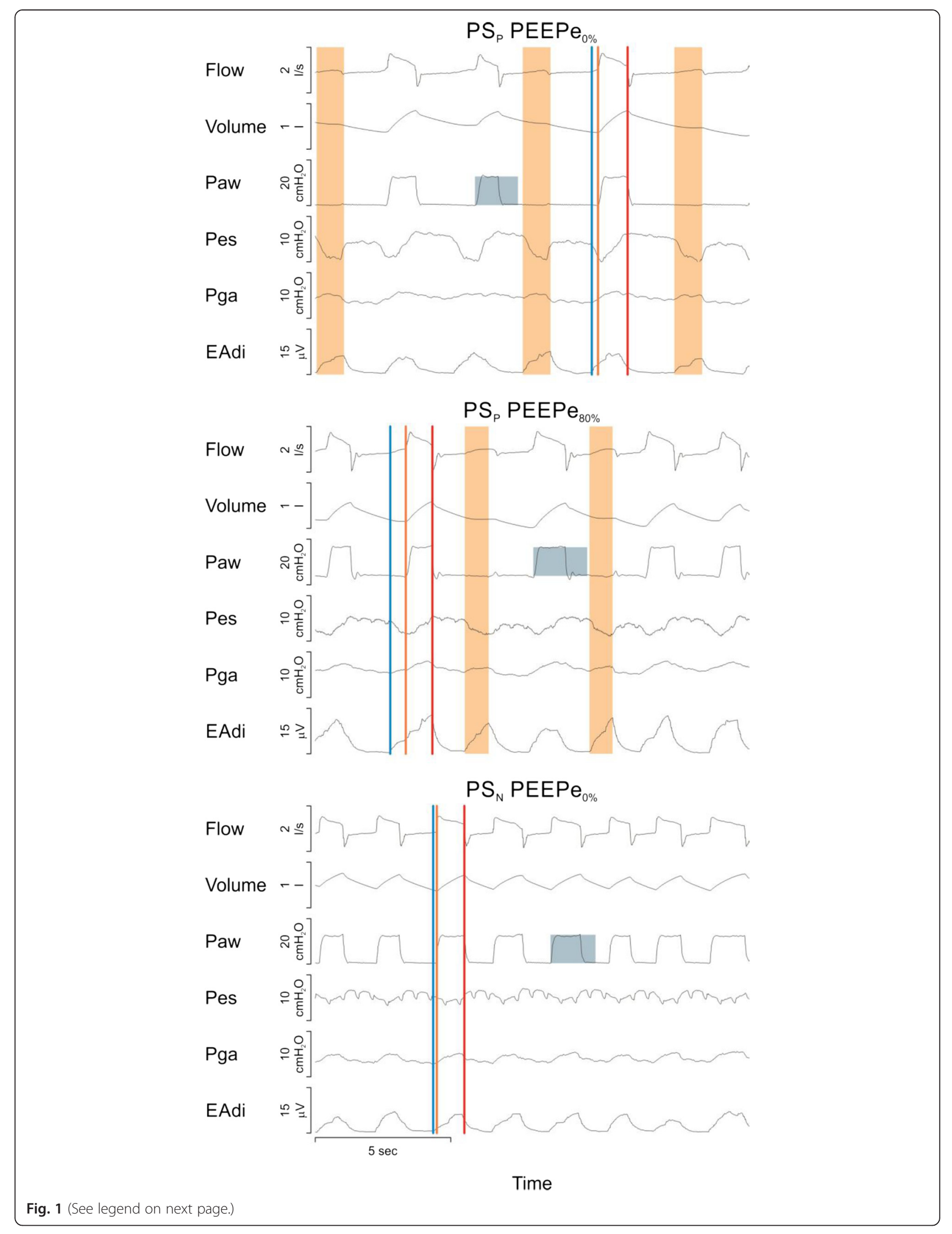


(See figure on previous page.)

Fig. 1 Time tracings from one individual patient. Time tracings of flow, volume, airway (Paw), esophageal (Pes) and gastric (Pga) pressures, and diaphragm electrical activity (EAdi) during pneumatically triggered and cycled-off pressure support $\left(P S_{P}\right)$ at $0 \%$ extrinsic positive end-expiratory pressure (PEEP $e_{0 \%}$ ) (top panel), PSP at PEEPe $80 \%$ (middle panel) and neurally triggered and cycled-off pressure support $\left(P S_{N}\right)$ at PEEPe $e_{0 \%}$ (bottom panel). Blue, orange and red lines indicate onset of diaphragm electrical activity (EAdi), nadir of Pes, and end of assistance, respectively. Orange bars indicate EAdi without assistance (ineffective efforts). A square wave pressure assistance profile of the same magnitude above positive end-expiratory pressure (PEEP) was obtained during all conditions (height of blue box same $\mathrm{cm} \mathrm{H}_{2} \mathrm{O}$ in all panels). $\mathrm{PS}_{\mathrm{N}}$ at PEEPe $e_{0 \%}$ synchronized the assistance and eliminated ineffective efforts. Pes was reduced by $\mathrm{PS}_{\mathrm{P}}$ at PEEPe $\mathrm{B}_{80}$ and $\mathrm{PS}_{\mathrm{N}}$ at $\mathrm{PEEPe_{0 \% }}$ whereas EAdi remained unchanged. The nadir of Pes occurred prior to the peak of EAdi and resulted in a positive inspiratory Pes deflection during all conditions, suggesting assistance delivery was too high in this subject. Note that Pes reverses from a negative to a positive trajectory as assistance starts, suggesting that assistance levels are excessive despite a tidal volume $\left(V_{T}\right)$ of $5.2 \mathrm{ml} / \mathrm{kg}$ of predicted body weight. Despite a low group-mean $V_{T}$, this type of Pes waveform was noted in at least $50 \%$ of the patients

Figure 2 shows the topographic distribution of timing errors for triggering (y-axis) and cycling-off ( $\mathrm{x}$-axis), respectively, for all patients. The red area indicates $80 \%$ of the most frequent patient-ventilator interactions for all breaths in all subjects during $\mathrm{PS}_{\mathrm{N}}$ (left panels) and $\mathrm{PS}_{\mathrm{P}}$ (right panels) during $\mathrm{PEEPe}_{0 \%}, \mathrm{PEEPe}_{40 \%}, \mathrm{PEEPe}_{80 \%}$, and $\mathrm{PEEPe}_{120 \%}$, (top to bottom). During $\mathrm{PS}_{\mathrm{N}}$ at $\mathrm{PEEPe}_{0 \%}$ triggering was concentrated within an area ranging from minus $5 \%$ to $25 \%$ for triggering error (Y-axis) and minus $5 \%$ to $5 \%$ error during cycling-off (x-axis) regardless of PEEPe (indicated by box).

During $\mathrm{PS}_{\mathrm{B}}$ there was a widespread variability ranging from about minus $10 \%$ to $60 \%$ for triggering error (yaxis) and about minus $30 \%$ to $30 \%$ error for cycling-off (x-axis), regardless of PEEPe. Regardless of PEEPe, less than $10 \%$ of breaths landed within the box during $\mathrm{PS}_{\mathrm{P}}$, compared to more than $80 \%$ during $\mathrm{PS}_{\mathrm{N}}$ (Table 3).

During $\mathrm{PS}_{\mathrm{N}}$ at $\mathrm{PEEPe}_{0 \%}, 52 \%(\mathrm{SD} \pm 30 \%)$ of all breaths were terminated by neural cycling-off at $70 \%$ of peak EAdi and at this point the inspiratory flow had decreased to $46 \%$ (SD $\pm 19 \%$ ) of peak flow. The remaining $48 \%$ (SD $\pm 30 \%$ ) of breaths were terminated earlier due to pressure exceeding the upper pressure limit by $3 \mathrm{~cm} \mathrm{H} 2 \mathrm{O}$ causing the $-5 \%$ cycling-off errors indicated in Fig. 2, left panel.

During $\mathrm{PS}_{\mathrm{N}}$, the NeuroSync index was consistently lower, indicating improved patient ventilator interaction, at all levels of PEEPe. Increasing PEEPe improved patientventilator interaction i.e., decreased NeuroSync index during $\mathrm{PS}_{\mathrm{P}}$ but had no effect during $\mathrm{PS}_{\mathrm{N}}$ (Table 3). Regarding severe asynchronies, EAdi without trigger (ineffective efforts) exceeded $10 \%$ in three patients $(12 \%, 12 \%$ and $20 \%$ ) during $\mathrm{PS}_{\mathrm{P}}$ (Table 3). Other asynchronies were not frequent during either $\mathrm{PS}_{\mathrm{P}}$ or $\mathrm{PS}_{\mathrm{N}}$.

\section{Neural (EAdi variables) and mechanical (Pes variables) effort}

Figure 3 shows the neural and mechanical effort for triggering and for the whole inspiration in all subjects, at all PEEPe levels, for $\mathrm{PS}_{\mathrm{N}}$ and $\mathrm{PS}_{\mathrm{P}}$. The corresponding statistics are provided in Table 4 for clarity. ÊAdi ${ }_{\text {TRIG }}$ was lower during $\mathrm{PS}_{\mathrm{N}}$ than $\mathrm{PS}_{\mathrm{P}}$ at all PEEPe levels. During $\mathrm{PS}_{\mathrm{N}}, \hat{E A d i}_{\mathrm{TRIG}}$ at $\mathrm{PEEPe}_{0 \%}$ was also lower compared to $\mathrm{PS}_{\mathrm{P}}$ at $\mathrm{PEEPe}_{80 \%}$ (Table 4). Increasing PEEPe decreased

Table 3 Patient ventilator interaction indices at different levels of PEEPe for $\mathrm{PS}_{\mathrm{P}}$ and $P S_{N}$

\begin{tabular}{|c|c|c|c|c|c|c|}
\hline Parameter & Mode & $\mathrm{PEEPe}_{0 \%}$ & $\mathrm{PEEPe}_{40 \%}$ & $\mathrm{PEEPe}_{80 \%}$ & $\mathrm{PEEPe}_{120 \%}$ & $P^{*}$ \\
\hline \multirow[t]{2}{*}{$\overline{T_{T R I G}(m s)}$} & $P S_{P}$ & $276(169,370)^{z}$ & $198(156,357)^{\mathrm{az}}$ & $183(143,312)^{\mathrm{abz}}$ & $154(33,236)^{\mathrm{abcz}}$ & $<0.001$ \\
\hline & $P S_{N}$ & $69(56,82)^{x}$ & $54(32,70)$ & $59(17,82)$ & $76(54,90)$ & \\
\hline \multirow[t]{2}{*}{$\mathrm{T}_{\text {CYC-OFF }}(\mathrm{ms})$} & $P S_{p}$ & $76(21,36)^{z}$ & $126(44,401)^{\mathrm{az}}$ & $130(47,432)^{\mathrm{abz}}$ & $106(14,314)^{\mathrm{abcz}}$ & $<0.001$ \\
\hline & $P S_{N}$ & $12(8,14)^{x}$ & $8(2,14)$ & $5(-2,12)$ & $2(-7,10)$ & \\
\hline \multirow[t]{2}{*}{ NeuroSync index (\%) } & $P S_{p}$ & $29.1(13.9,46.8)^{z}$ & $25.3(15.5,40.9)^{\mathrm{az}}$ & $20.6(13.5,37.1)^{\mathrm{abz}}$ & $17.7(10.5,38.9)^{\mathrm{abcz}}$ & $<0.001$ \\
\hline & $P S_{N}$ & $5.6(4.2,7.8)^{\times}$ & $6.0(4.9,8.3)$ & $6.2(5.1,8.5)$ & $6.7(3.8,10.3)$ & \\
\hline \multirow[t]{2}{*}{ EAdi without assist (\%) } & $P S_{P}$ & $0.8(0,10.1)$ & $1.1(0,18.7)$ & $0(0,10.8)$ & $0(0,11.4)$ & $<0.001$ \\
\hline & $P S_{N}$ & $0(0,0)$ & $0(0,0)$ & $0(0,0)$ & $0(0,0)$ & \\
\hline \multirow[t]{2}{*}{ Synchrony (inside box) (\%) } & $P S_{P}$ & $4.7(0,16.3)^{\mathrm{z}}$ & $7.8(0,20)^{\mathrm{az}}$ & $11.5(0,37.4)^{\mathrm{abz}}$ & $7(0.2,46.3)^{\mathrm{abcz}}$ & $<0.001$ \\
\hline & $P S_{N}$ & $89.4(76.2,97.9)^{x}$ & $91.3(76,95.7)$ & $88(78,93)$ & $80(63.4,97.4)$ & \\
\hline \multirow[t]{2}{*}{ Dyssynchrony (outside box) (\%) } & $P S_{p}$ & $83.5(76.3,92)^{z}$ & $79.3(63,86.7)^{a z}$ & $76.9(62,87.5)^{\mathrm{abz}}$ & $70.9(52.3,89.3)^{\mathrm{abcz}}$ & $<0.001$ \\
\hline & $P S_{N}$ & $9(2.1,23.1)^{x}$ & $7.3(1.8,21.1)$ & $10.8(6.5,17.4)$ & $18.6(2.1,32.7)$ & \\
\hline
\end{tabular}

Values are presented as median (25-75\% interquartile range). ${ }^{*} P$ values for one-way repeated measures analysis of variance on ranks for the eight conditions: within the same mode: ${ }^{\mathrm{a}} P<0.05$ compared to extrinsic positive end-expiratory pressure $(\mathrm{PEEPe})_{0 \%} ;{ }^{\mathrm{b}} P<0.05$ compared to $\mathrm{PEEPe} \mathrm{e}_{40 \% ;}{ }^{\mathrm{C}} P<0.05$ compared to $\mathrm{PEEPe} \mathrm{e}_{80 \%}$. Between modes: ${ }^{z} P<0.05$ compared to $P_{N}$ at same PEEPe. Comparison of $P_{N}$ zero PEEP to $P_{P}$ optimal $P E E P:{ }^{x} P<0.05 P E E P e_{0 \%}$ at $P S_{N}$ Vs. $P E E P e_{80 \%}$ at $P S_{P} . P S_{P}$ pneumatically triggered and cycled-off pressure support, $P S_{N}$ neurally triggered and cycled-off pressure support ventilation, $P E E P e$ extrinsic $P E E P, T_{T R I G}$ diaphragm electrical activity (EAdi)-to-trigger time difference, $T_{\text {CYC-OFF }}$ cycling-off timing difference 


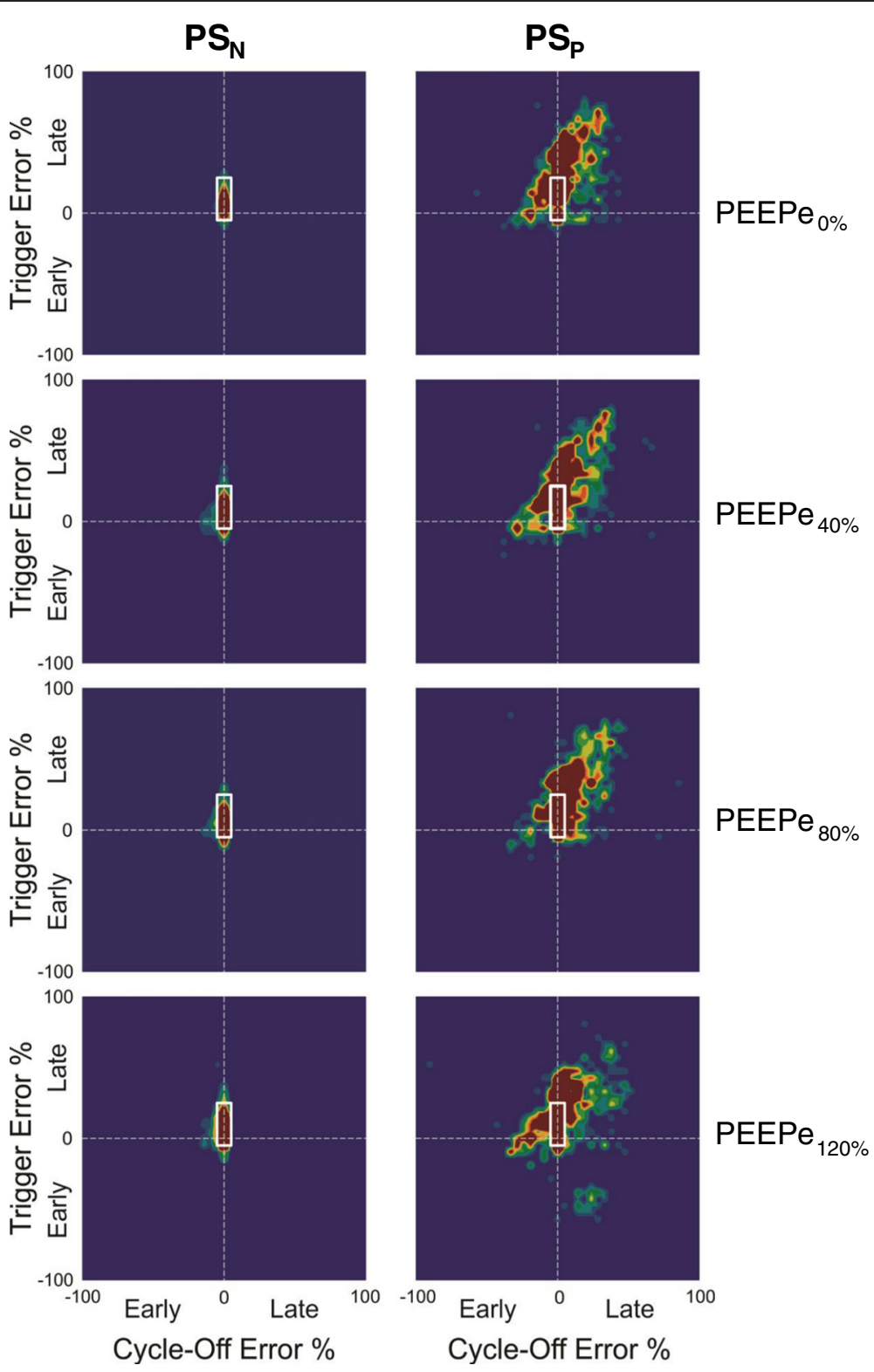

Fig. 2 Patient-ventilator interaction for all patients represented topographically. Topographic distribution of triggering error (y-axis) and cycling-off error ( $\mathrm{X}$-axis). The red area indicates $80 \%$ of the most frequent patient-ventilator interactions for all breaths in all subjects during neurally triggered and cycled-off pressure support $\left(P S_{N}\right)$ (left panels) and pneumatically triggered and cycled-off pressure support (PSP) (right panels) during extrinsic positive

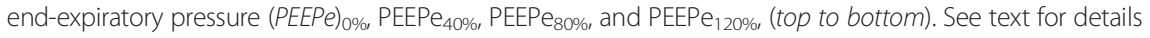

$\hat{E}$ Adi $_{\text {TRIG }}$ during both $\mathrm{PS}_{\mathrm{P}}$ and $\mathrm{PS}_{\mathrm{N}}$. ÊAdi ${ }_{\mathrm{TOT}}$ was not significantly between $\mathrm{PS}_{\mathrm{P}}$ and $\mathrm{PS}_{\mathrm{N}}$, nor did it change with changing PEEPe.

Both $\Delta \overline{\mathrm{P}}_{\mathrm{TR}}$ and $\Delta \overline{\mathrm{P}}_{\mathrm{TOOT}}$ were higher during $\mathrm{PS}_{\mathrm{P}}$ compared to $\mathrm{PS}_{\mathrm{N}}$ at the same PEEPe (Fig. 3 and Table 4): $\Delta \overline{\mathrm{P}} \mathrm{S}_{\mathrm{TRIG}}$ was consistently and markedly reduced during $\mathrm{PS}_{\mathrm{N}}$ compared to $\mathrm{PS}_{\mathrm{P}}$. Increasing $\mathrm{PEEPe}$ reduced $\Delta \overline{\mathrm{P}}_{\text {TRIG }}$ during $\mathrm{PS}_{\mathrm{P}}$ at $\mathrm{PEEPe}_{80 \%}$ but did not change during $\mathrm{PS}_{\mathrm{N}}: \Delta \overline{\mathrm{P}} \mathrm{S}_{\mathrm{TOT}}$ decreased with increasing PEEPe during both $\mathrm{PS}_{\mathrm{P}}$ and $\mathrm{PS}_{\mathrm{N}}$. Four patients had positive
$\Delta \overline{\mathrm{P}}_{\mathrm{TOT}}$ during $\mathrm{PS}_{\mathrm{P}}$ at $\mathrm{PEEPe}_{80 \%}$ and one patient had positive $\Delta \overline{\mathrm{P}}_{\mathrm{TOT}}$ during $\mathrm{PS}_{\mathrm{N}}$ at $\mathrm{PEEPe}_{0 \%}$. Figure 4 shows that the change in total mechanical efforts between $\mathrm{PS}_{\mathrm{P}}$ at $\mathrm{PEEPe}_{0 \%}$ and $\mathrm{PS}_{\mathrm{N}}$ at $\mathrm{PEEPe}_{0 \%}$ (x-axis) is similar to the change between $\mathrm{PS}_{\mathrm{P}}$ at $\mathrm{PEEPe}_{0 \%}$ and $\mathrm{PS}_{\mathrm{P}}$ at $\mathrm{PEEPe}_{80 \%}$ (with strong correlation: $R^{2}=0.77$ for $\Delta \overline{\mathrm{Pes}} \mathrm{TOT}_{\mathrm{TO}}$ and $R^{2}=0.68$ for $\mathrm{PTPes}_{\mathrm{TOT}}$ ).

$\Delta \overline{\mathrm{P}} \mathrm{es} / \Delta \overline{\mathrm{P}}_{\mathrm{L}}$ ranged between 2.2 and $24.5 \%$, decreased with increasing PEEPe during both $\mathrm{PS}_{\mathrm{P}}$ and $\mathrm{PS}_{\mathrm{N}}$, and was lower during $\mathrm{PS}_{\mathrm{N}}$ (Table 4). 


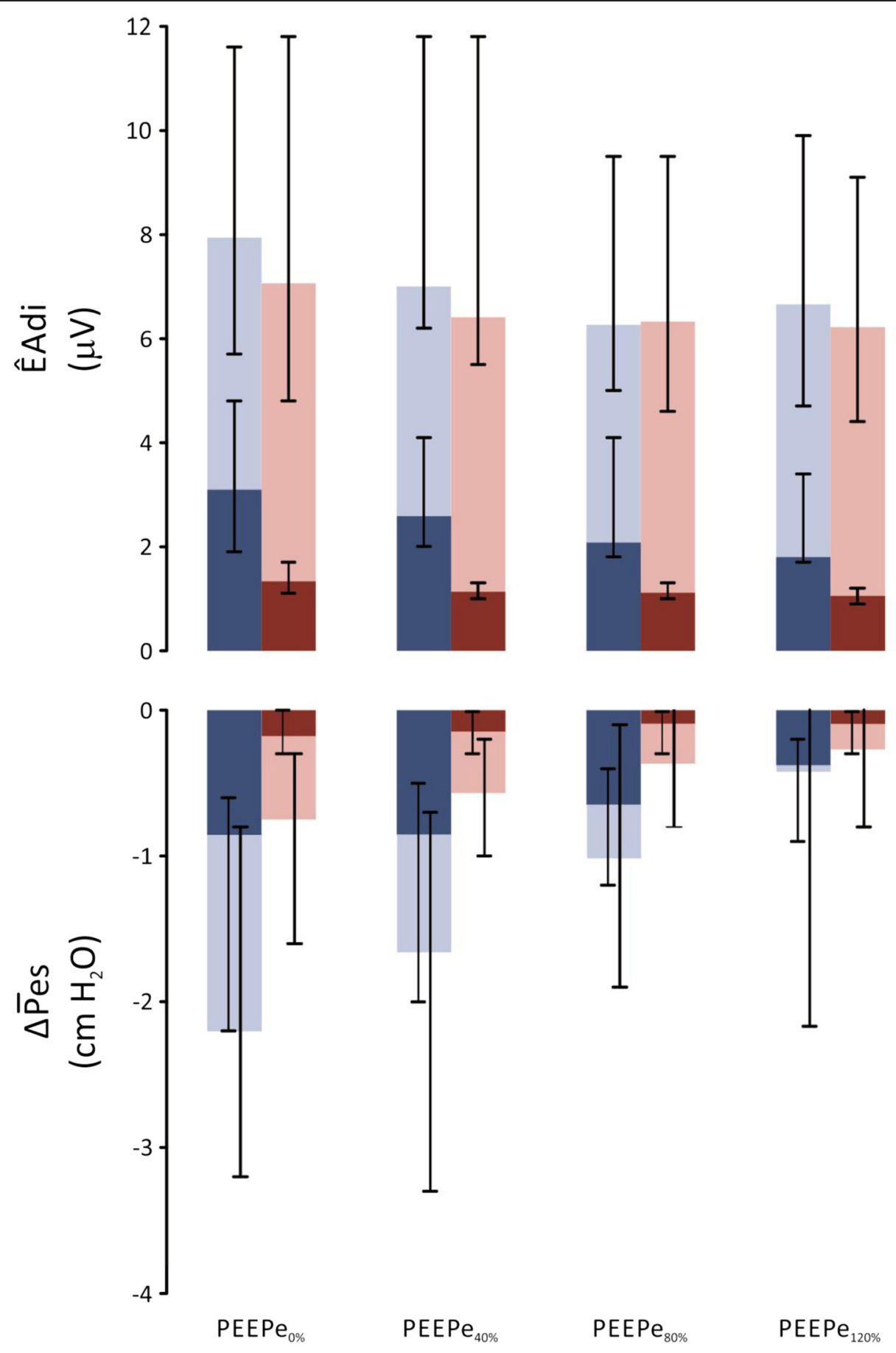

Fig. 3 Neural and mechanical effort during neurally triggered and cycled-off pressure support $\left(P S_{N}\right)$ and pneumatically triggered and cycled-off pressure support $\left(P S_{P}\right)$ at different levels of extrinsic positive end-expiratory pressure (PEEPe). Top panel: peak diaphragm electrical activity (EAdi, $y$-axis) for $\mathrm{PS}_{\mathrm{P}}$ (blue bars) and $\mathrm{PS}_{\mathrm{N}}$ (red bars) for triggering (darker bars) and total inspiration (darker bars + lighter bars) with increasing PEEPe (x-axis). Bottom panel: mean inspiratory deflection in esophageal pressure $\left(\Delta \bar{P} e s, y\right.$-axis) for $P S_{P}$ (blue bars) and $\mathrm{PS}_{\mathrm{N}}$ (red bars) for triggering (darker bars) and total inspiration (darker bars + lighter bars) with increasing PEEPe ( $x$-axis). Median and interquartile ranges are presented. For clarity, a corresponding statistical description is provided in Table 4

\section{Neuromechanical efficiency (NME)}

Neuromechanical efficiency at the same PEEPe was lower during $\mathrm{PS}_{\mathrm{N}}$ compared to $\mathrm{PS}_{\mathrm{P}}$ and decreased with increasing PEEPe during both $\mathrm{PS}_{\mathrm{P}}$ and $\mathrm{PS}_{\mathrm{N}}$ (Table 4). There was no difference in NME between $\mathrm{PS}_{\mathrm{N}}$ at $\mathrm{PEEPe}_{0 \%}$ and $\mathrm{PS}_{\mathrm{P}}$ at $\mathrm{PEEPe}_{80 \%}$. The reduction in NME from 
Table 4 Neural and mechanical indices of respiratory effort at different levels of PEEPe during PSP and PS

\begin{tabular}{|c|c|c|c|c|c|c|}
\hline Parameter & Mode & $\mathrm{PEEPe}_{0 \%}$ & $\mathrm{PEEPe}_{40 \%}$ & $\mathrm{PEEPe}_{80 \%}$ & $\mathrm{PEEPe}_{120 \%}$ & $P^{*}$ \\
\hline \multirow[t]{2}{*}{$\Delta \bar{P}_{\text {TRIG }}\left(\mathrm{cm} \mathrm{H}_{2} \mathrm{O}\right)$} & $P S_{p}$ & $-0.9(-2.2,-0.6)^{z}$ & $-0.9(-2.0,-0.5)^{z}$ & $-0.6(-1.2,-0.4)^{\mathrm{abz}}$ & $-0.4(-0.9,-0.2)^{\mathrm{abcz}}$ & \multirow[t]{2}{*}{$<0.00$} \\
\hline & $P S_{N}$ & $-0.2(-0.3,-0.0)^{x}$ & $-0.1(-0.3,-0.0)$ & $-0.1(-0.3,-0.0)$ & $-0.1(-0.3,-0.0)$ & \\
\hline \multirow[t]{2}{*}{$\Delta \overline{\mathrm{P}}_{\text {Tот }}\left(\mathrm{cm} \mathrm{H}_{2} \mathrm{O}\right)$} & $P S_{p}$ & $-2.2(-3.2,-0.8)^{z}$ & $-1.7(-3.3,-0.7)^{z}$ & $-1.0(-1.9,-0.1)^{\mathrm{abz}}$ & $-0.4(-2.2,0.2)^{a c z}$ & \multirow[t]{2}{*}{$<0.00$} \\
\hline & $P S_{N}$ & $-0.7(-1.6,-0.3)$ & $-0.6(-1.0,-0.2)^{\mathrm{a}}$ & $-0.4(-0.8,0.4)^{\mathrm{ab}}$ & $-0.3(-0.8,0.4)^{\mathrm{abc}}$ & \\
\hline \multirow[t]{2}{*}{ PTPes $_{\text {TRIG }}\left(\mathrm{cm} \mathrm{H}_{2} \mathrm{O}^{*} \mathrm{~S} / \mathrm{min}\right)$} & $P S_{P}$ & $-5.0(-23.8,-2.7)^{z}$ & $-3.3(-19.4,-1.5)^{z}$ & $-2.4(-10.5,-1.1)^{\mathrm{abz}}$ & $-1.3(-4.2,-0.3)^{\mathrm{abcz}}$ & \multirow[t]{2}{*}{$<0.00$} \\
\hline & $P S_{N}$ & $-0.2(-0.6,-0.1)^{x}$ & $-0.2(-0.4,-0.0)$ & $-0.0(-0.3,0.1)$ & $-0.1(-0.4,0.0)$ & \\
\hline \multirow[t]{2}{*}{ PTPestot $\left(\mathrm{cm} \mathrm{H}_{2} \mathrm{O}^{*} \mathrm{~s} / \mathrm{min}\right)$} & $P S_{p}$ & $-44.5(-81.3,-13.9)^{z}$ & $-29.7(-58.3,-11.5)^{z}$ & $-17(-34.2,-2.6)^{\mathrm{abz}}$ & $-7.3(-49.8,3.0)^{\mathrm{abcz}}$ & \multirow[t]{2}{*}{$<0.00$} \\
\hline & $P S_{N}$ & $-15.8(-27.7,-5.9)$ & $-11.5(-16.7,-4.9)^{\mathrm{a}}$ & $-7.5(-15.4,5.5)^{\mathrm{ab}}$ & $-5.1(-14.1,4.2)^{\mathrm{abc}}$ & \\
\hline \multirow[t]{2}{*}{$\hat{\text { EAditRIG }}(\mu \mathrm{V})$} & $P S_{P}$ & $3.1(1.9,4.8)^{z}$ & $2.6(2.0,4.1)^{z}$ & $2.1(1.8,4.1)^{\mathrm{abz}}$ & $1.8(1.7,3.4)^{\mathrm{abcz}}$ & \multirow[t]{2}{*}{$<0.00$} \\
\hline & $P S_{N}$ & $1.3(1.1,1.7)^{x}$ & $1.1(1.0,1.3)^{\mathrm{a}}$ & $1.1(1.0,1.3)^{\mathrm{ab}}$ & $1.0(0.9,1.2)^{\mathrm{ab}}$ & \\
\hline \multirow[t]{2}{*}{ ÉAdi ${ }_{\text {TOT }}(\mu \mathrm{V})$} & $P S_{P}$ & $7.9(5.7,11.6)$ & $7.0(6.2,11.8)$ & $6.3(5.0,9.5)$ & $6.7(4.7,9.9)$ & \multirow[t]{2}{*}{$<0.00$} \\
\hline & $P S_{N}$ & $7.1(4.8,11.8)$ & $6.4(5.5,11.8)$ & $6.3(4.6,9.5)$ & $6.2(4.4,9.1)$ & \\
\hline \multirow[t]{2}{*}{$\Delta \overline{\mathrm{P}} \mathrm{es} / \Delta \overline{\mathrm{P}}_{\mathrm{L}}(\%)$} & $P S_{P}$ & $24.5(35.4,11.0)^{z}$ & $18.2(29.8,8.3)^{z}$ & $12.5(22.7,1.3)^{\mathrm{abz}}$ & $6.6(21.1,-2.70)^{a b c z}$ & \multirow[t]{2}{*}{$<0.00$} \\
\hline & $P S_{N}$ & $7.0(12.1,2.9)^{x}$ & $5.4(6.9,2.2)$ & $2.8(7.6,-4.5)^{\mathrm{ab}}$ & $2.2(7.6,-5.1)^{\mathrm{abc}}$ & \\
\hline \multirow[t]{2}{*}{$\mathrm{NME}\left(\mathrm{cm} \mathrm{H}_{2} \mathrm{O} / \mu \mathrm{V}\right)$} & $P S_{P}$ & $-0.27(-0.34,-0.16)^{z}$ & $-0.22(-0.32,-0.11)^{\mathrm{az}}$ & $-0.13(-0.28,-0.03)^{\mathrm{abz}}$ & $-0.09(-0.15,0.02)^{\mathrm{abcz}}$ & \multirow[t]{2}{*}{$<0.00$} \\
\hline & $P S_{N}$ & $-0.11(-0.22,-0.04)$ & $-0.07(-0.15,-0.03)^{\mathrm{a}}$ & $-0.06(-0.10,0.04)^{\mathrm{ab}}$ & $-0.05(0.08,0.06)^{\mathrm{abc}}$ & \\
\hline
\end{tabular}

Values are presented as median (25-75 \% interquartile range). ${ }^{*} P$ values for one-way repeated measures analysis of variance on ranks for the eight conditions: -within the same mode: ${ }^{\mathrm{a}} P<0.05$ compared to $P E E P e_{0 \% ;}{ }^{b} P<0.05$ compared to $P E E P e_{40 \% ;}{ }^{c} P<0.05$ compared to $P E E P e_{80 \%}$. Between modes: ${ }^{z} P<0.05$ compared to $\mathrm{PS}_{\mathrm{N}}$ at same PEEPe comparison of $\mathrm{PS}_{\mathrm{N}}$ zero PEEP to $P S_{\mathrm{P}}$ optimal PEEP: ${ }^{\mathrm{x}} \mathrm{P}<0.05 \mathrm{PEEPe}_{0 \%}$ at $\mathrm{PS}_{\mathrm{N}} \mathrm{Vs}$. $P E E P \mathrm{P}_{80 \%}$ at $P S_{\mathrm{P}}$. $P S_{P}$ pneumatically triggered and cycled-off pressure support, $P S_{N}$ neurally triggered and cycled-off pressure support ventilation, $\triangle \bar{P}$ S $_{T R I G}$ pre-trigger mean deflection of esophageal pressure, $\triangle \bar{P} e_{T O T}$ total inspiratory mean deflection for esophageal pressure, $P T P$ S $_{T O T}$ total inspiratory pressure time product per minute for esophageal pressure, $P$ TPes ${ }_{T R I G}$ pre-trigger pressure time product per minute for esophageal pressure, $\hat{E} A d i_{T O T}$ peak inspiratory diaphragm electrical activity (EAdi) for total inspiration, $\hat{E} A d i_{T R I G}$ peak pre-trigger EAdi, $\Delta \bar{P} e s / \Delta \bar{P}_{L}$ esophageal pressure contribution to transpulmonary pressure during inspiration, $N M E$ neuromechanical efficiency calculated for esophageal pressure

$\mathrm{PEEPe}_{0 \%}$ to $\mathrm{PEEPe}_{80 \%}$ during $\mathrm{PS}_{\mathrm{P}}$ was not different $(P=$ 0.699 ) for patients with EFL (median $28 \%, 25^{\text {th }}-75^{\text {th }}$ percentile 14-46 \%) and without EFL (41, 14-75\%).

\section{Discussion}

This study shows that neurally controlled pressure support improves patient-ventilator interaction, nearly abolishes pre-trigger inspiratory neural and mechanical effort, and shows - even when zero PEEP is applied - similar total inspiratory neural and mechanical effort as conventional pressure support with an optimal PEEPe. The main strength of the study is that it is the first to show that both neural monitoring and neural control of patient-ventilator interaction in patients with PEEPi are superior to pneumatic monitoring and pneumatic control of pressure support.

\section{Patient-ventilator interaction}

In agreement with previous studies [5, 10, 12-16], increasing PEEPe during $\mathrm{PS}_{\mathrm{P}}$ reduced the trigger delay. As hypothesized, the EAdi trigger-synchronization nearly abolished both neural and mechanical pre-trigger efforts regardless of PEEPe. Our results showing that both neural and mechanical pre-trigger efforts were reduced with increasing PEEPe during $\mathrm{PS}_{\mathrm{P}}$ confirms that application of PEEPe counteracts PEEPi and reduces pre-trigger mechanical effort with pneumatic triggering [5], although not as efficiently as during neural triggering, similar to the recent work of Bellani [10].

Cycling-off assistance in PS mode is conventionally based on the relative reduction in inspiratory flow. This algorithm is an oversimplification and not physiologically sound, as flow during ventilatory assistance is influenced by multiple factors, such as respiratory system time constant, neural inspiratory time, level of pressure support, and inspiratory muscle pressure [17]. In the present study, the cycling-off setting was $30 \%$ of peak inspiratory flow (default setting of the ventilator utilized). This choice could be critiqued as being too low in sensitivity in COPD patients as percentages from 40 to $70 \%$ have been suggested as more feasible $[6,7]$. As there are no guidelines on how to adjust cycling-off for each individual patient, we opted to stay within default settings.

In support of cycling-off at $70 \%$ of peak EAdi being feasible was our finding that assistance was either EAditerminated when flow corresponded to $46 \%$ of peak flow or immediately before EAdi termination due to the inspiratory muscle relaxation increasing pressure in the circuit by $3 \mathrm{~cm} \mathrm{H} \mathrm{H}_{2} \mathrm{O}$ above the targeted pressure (ServoI manual). Thus the $\mathrm{PS}_{\mathrm{N}}$ cycling-off in the present study coincides with suggested flow cycling-off at $40-70 \%$ of peak flow in COPD $[6,7]$.

$\mathrm{PS}_{\mathrm{N}}$ showed high precision of triggering and cyclingoff of pressure relative to the neural effort and centered 


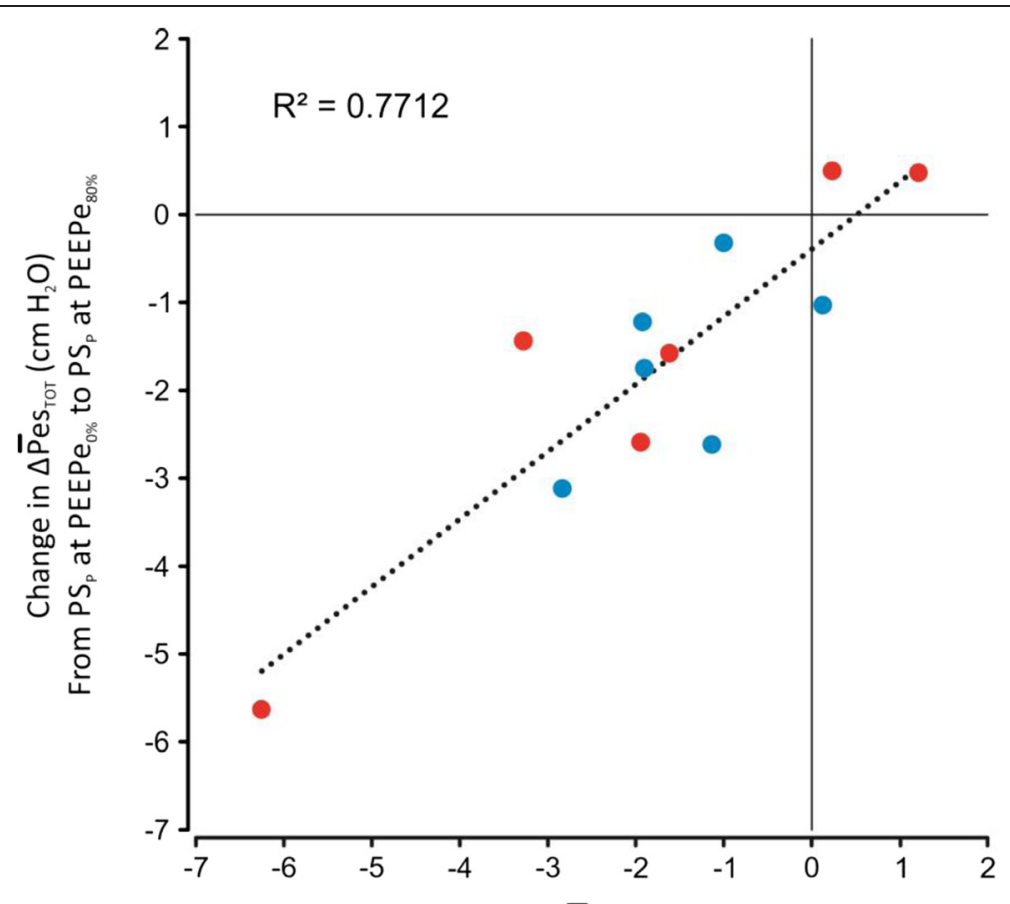

Change in $\Delta \overline{\mathrm{P}}_{\text {eS }}\left(\mathrm{cm} \mathrm{H}_{2} \mathrm{O}\right)$

From $P S_{P}$ at $P E E P e_{0 \%}$ to $P S_{N}$ at $P E E P e_{0 \%}$

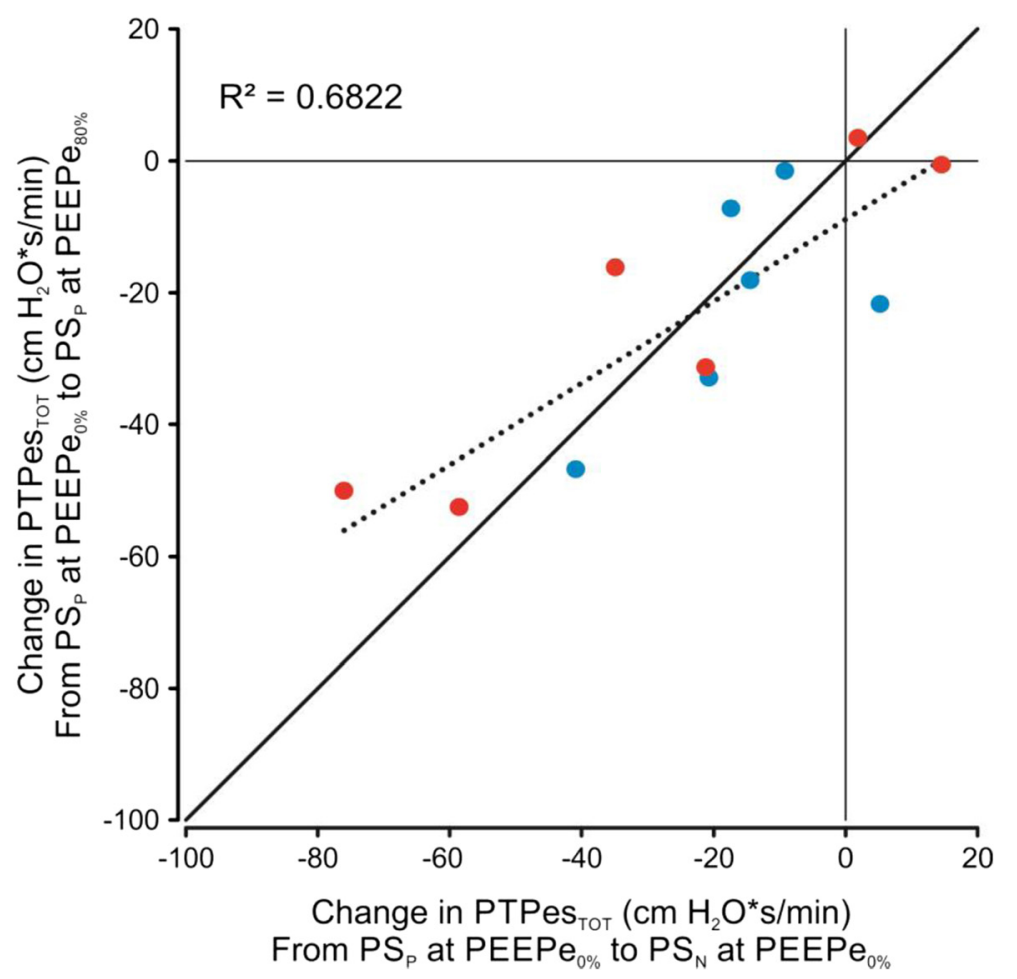

Fig. 4 (See legend on next page.) 
(See figure on previous page.)

Fig. 4 Comparison of the changes in mechanical effort for all subjects. Changes in total mechanical effort from pneumatically triggered and cycled-off pressure support $\left(P S_{P}\right)$ at extrinsic positive end-expiratory pressure $(P E E P e)_{0} \%$ to neurally triggered and cycled-off pressure support $\left(P S_{N}\right)$

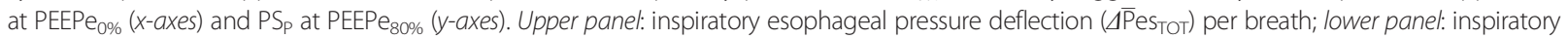
pressure time product per minute (PTPes TOT). Blue symbols indicate patients with expiratory flow limitation; red symbols indicate patients without expiratory flow limitation. See text for details

$80 \%$ of breaths within a narrow range of error (Fig. 2). In contrast, $\mathrm{PS}_{\mathrm{P}}$ showed poor precision of both triggering and cycling-off relative to the neural effort. Although group median values indicated delays (Table 3), the topographical distribution of all breaths and in all subjects shows that ventilatory assistance could start and cycle off prematurely. It is questionable if adjustment of trigger and cycling-off settings during $\mathrm{PS}_{\mathrm{P}}$ could have corrected this extreme heterogeneity of timing of assist relative to neural inspiratory effort.

With regards to the overall patient-ventilator interaction, a low NeuroSync index and little inter-individual variability, confirms the effectiveness of $\mathrm{PS}_{\mathrm{N}}$ to synchronize assistance in the presence of PEEPi. Although improved by increasing PEEPe, the NeuroSync index was at least three times higher (worse patient-ventilator interaction) during $\mathrm{PS}_{\mathrm{P}}$ mainly due to dys-synchrony i.e., trigger and cycling-off errors, which cannot be determined with pressure-flow-volume waveform analysis without EAdi $[11,18]$. The low incidence of other asynchronies e.g., ineffective efforts and auto-triggering is in agreement with previous work by Thille [19] showing that limiting $\mathrm{V}_{\mathrm{T}}(6 \mathrm{ml} / \mathrm{kg})$ - as in the present study - improves patient ventilator interaction during $\mathrm{PS}_{\mathrm{P}}$. However, three patients $(25 \%)$ approached a high frequency of EAdi-without-assistance (ineffective efforts) during $\mathrm{PS}_{\mathrm{P}}$ which is recognized as severe asynchrony and associated with adverse outcomes such as increased duration of mechanical ventilation [20, 21].

With regards to the effort throughout the entire inspiration, our results (Fig. 4) indicating that reductions from $\mathrm{PEEPe}_{0 \%}$ during $\mathrm{PS}_{\mathrm{P}}$ to $\mathrm{PEEP}_{0 \%}$ during $\mathrm{PS}_{\mathrm{N}}$ equaled those from $\mathrm{PEEPe}_{0 \%}$ during $\mathrm{PS}_{\mathrm{P}}$ to $\mathrm{PEEP}_{80 \%}$ during $\mathrm{PS}_{\mathrm{P}}$ support our assumption that synchronized assist overcomes PEEPi in COPD patients without the need to apply PEEPe. Thus, neural triggering allows a unique starting point for assistance delivery during every breath regardless of hyperinflation and PEEPi, however, the subsequent inspiration requires that the combined patient effort and assistance (i.e., the transpulmonary pressure) is sufficient to overcome the respiratory system's resistive and elastic forces. In contrast, $\mathrm{PS}_{\mathrm{P}}$ and fixed PEEPe only compensate for the estimated average increase in elastic recoil at end-expiration due to dynamic hyperinflation and cannot correct for breath-by-breath changes in PEEPi.
Our results that applying PEEPe during $\mathrm{PS}_{\mathrm{P}}$ reduced mechanical effort for the entire inspiration agree with previous studies $[4,5]$. A curious observation of the present study was that the reduction in total inspiratory mechanical effort from PEEP $_{0 \%}$ to PEEP $_{80 \%}$ during $\mathrm{PS}_{\mathrm{P}}$ was larger than what could be explained by the reductions in pre-trigger mechanical effort. Even more confounding, increasing PEEPe actually reduced total inspiratory mechanical effort during $\mathrm{PS}_{\mathrm{N}}$; a decrease that could not be attributed to reductions in the pre-trigger mechanical effort, as it was already abolished by the neural triggering. A likely possibility for why the mechanical efforts decreased is that PEEPe induced hyperinflation (increased end expiratory lung volume) which would explain the reduction in NME (less pressure for a given neural output).

This is the first study measuring the effect of PEEPe on neural effort strictly in COPD patients (the work of Bellani [10] included $50 \%$ COPD patients). Although our results showed that pre-trigger neural effort could be reduced by increasing PEEPe during $\mathrm{PS}_{\mathrm{B}}$ the total neural inspiratory effort did not reach a significant decrease with increasing PEEPe during $\mathrm{PS}_{\mathrm{P}}$ nor during $\mathrm{PS}_{\mathrm{N}}$. This supports our thought that reduced total inspiratory mechanical effort with increasing PEEPe were in part associated with hyperinflation-induced respiratory muscle weakness [22], and not de-activation of the muscles. Previous studies indicate that application of CPAP (Continuous Positive Airway Pressure) in COPD patients with PEEPi increases end-expiratory lung volume $[4,23]$. However, it has been suggested that application of PEEPe below the level of PEEPi in patients with EFL does not increase hyperinflation [24]. Our results did not indicate a difference for NME between patients with and without EFL. However, the present study showed a reduction in NME with increasing PEEPe during both $\mathrm{PS}_{\mathrm{P}}$ and $\mathrm{PS}_{\mathrm{N}}$, which could have been attributed to impaired contractility due to hyperinflation [22]. Thus, our finding that the total inspiratory mechanical effort during $\mathrm{PS}_{\mathrm{N}}$ at $\mathrm{PEEPe}_{0 \%}$, matched $\mathrm{PS}_{\mathrm{P}}$ at $\mathrm{PEEPe} \mathrm{P}_{80 \%}$ suggests that neural triggering is at least as efficient as titration of PEEPe to overcome PEEPi, and reduce total inspiratory mechanical effort. However, both methods pay a toll in terms of reduced NME.

It is important to point out that several patients received too high assistance (approximately $10 \mathrm{~cm} \mathrm{H}_{2} \mathrm{O}$ PS above PEEPe), resulting in low values of total inspiratory 
mechanical effort $\left(<2.5 \mathrm{~cm} \mathrm{H}_{2} \mathrm{O}\right.$ Pes), suggesting that the patient's contribution to tidal volume was very low. At this high level of unloading, further reduction in neural inspiratory effort is limited [25-27], which could explain the modest decrease in total neural inspiratory effort.

Despite relatively low $\mathrm{V}_{\mathrm{T}}$ targeted in the present study, which should contradict the notion of over-assistance [19], $\mathrm{PaCO}_{2}$ values were low, suggesting that certain patients could have been subjected to hyperventilation. Yet, another factor to explain the low total inspiratory mechanical effort could be respiratory muscle weakness. A limitation was that we did not evaluate respiratory effort sensation or dyspnea, which could have added insight to the issue of PEEPe and assistance levels that were too high. Note that with $\mathrm{PS}_{\mathrm{N}}$, the amount of pressure support delivered should be greater than PEEPi. If the initial pressure delivery is not adequate to counteract PEEPi, the elastic recoil in the system would cause an increase in airway pressure [10] (see Fig. 4 in that report), and would activate the cycling-off (pressure algorithm) used with neural control of PS (as the safety algorithm).

Despite PEEPe being demonstrated to reduce PEEPi and work of breathing, many factors of how to implement PEEPe are unclear [4]. It is not clear whether PEEPi should be expressed in terms of its dynamic PEEPi or static PEEPi components. In spontaneously breathing, mechanically ventilated patients with active expiration there are currently no methods available to reliably determine the optimal level of static PEEPi and there is ongoing evaluation of reliability in different methods determining dynamic PEEPi [12, 28-30]. Moreover, the implementation of bias flow for the use of flow-trigger creates further complication as it underestimates dynamic PEEPi [31]. Maltais et al. [32] reported that in paralyzed patients, dynamic PEEPi underestimates static PEEPi due to regional differences of mechanical properties within the lungs. We therefore opted to measure static PEEPi during VCV in the absence of spontaneous breathing effort.

One limitation of the present study was that we could not randomize $\mathrm{PS}_{\mathrm{P}}$ and $\mathrm{PS}_{\mathrm{N}}$, because $\mathrm{PS}_{\mathrm{P}}$ had to be adjusted first (with a target tidal volume of $6 \mathrm{ml} / \mathrm{kg}$ ), in order to be matched with the upper pressure limits that were obtained during $\mathrm{PS}_{\mathrm{N}}$. We did, however, randomize the ascending or descending order of the applied PEEPe in both arms, albeit we acknowledge that randomizing all PEEPe levels would be preferred. Due to risk of the steps between PEEPe levels being too large we decided not to randomize the order in which PEEPe was applied, but to apply PEEPe in either progressively increasing or decreasing order.

\section{Conclusion}

The present study shows that $\mathrm{PS}_{\mathrm{N}}$ overcomes the need for PEEPe to overcome PEEPi in COPD patients. $\mathrm{PS}_{\mathrm{N}}$ improves patient-ventilator interaction and reduces inspiratory mechanical effort to breathe. Although the present study suggests that $\mathrm{PS}_{\mathrm{N}}$ (at zero PEEP) can efficiently replace $\mathrm{PS}_{\mathrm{P}}$ with optimal PEEPe, use of PEEPe for other reasons, e.g., alveolar recruitment, would of course still apply. The clinical importance of improving patientventilator interaction in COPD remains to be studied.

\section{Key messages}

- Neurally controlled pressure support ventilation is feasible in patients with COPD demonstrating intrinsic PEEP

- Neurally controlled pressure support, compared to conventional, pneumatically controlled pressure support, improves patient-ventilator interaction and reduces inspiratory effort, even in the absence of external PEEP

- Neurally controlled pressure support overcomes the need for extrinsic PEEP, in order to overcome intrinsic PEEP in COPD patients

\section{Abbreviations}

$\mathrm{Bf}$ : breathing frequency; $\mathrm{Bf}_{\mathrm{N}}$ : neural breathing frequency; $\mathrm{COPD}$ : chronic obstructive pulmonary disease; CV: coefficient of variation; EAdi: diaphragm electrical activity; ÊAdi: peak inspiratory EAdi; ÊAdi TRIG: peak pre-trigger EAdi; EFL: expiratory flow limitation; $F_{E V}$ : forced expiratory volume in one second; FEV ${ }_{1} / F V C$ : forced vital capacity rate of one second; MAP: mean arterial pressure; NAVA: neurally adjusted ventilatory assist; NME: neuromechanical efficiency; $\mathrm{PaCO}_{2}$ : arterial carbon dioxide tension; $\mathrm{PaO}_{2} / \mathrm{FiO}_{2}$ : oxygenation index; Paw: airway pressure; $\bar{P}$ aw: mean airway pressure; PEEPe: extrinsic positive end-expiratory pressure; PEEP $e_{0 \%}$ : PEEPe levels of $0 \%$ of PEEPi STAT; $_{\text {i }}$ PEEPe $_{120 \%}$ : PEEPe levels of $120 \%$ of PEEPi STAT; PEEP $_{40 \%}$ : PEEPe levels of $40 \%$ of PEEPi STAT; $_{\text {PEEP }}$ 80\%: PEEPe levels of $80 \%$ of PEEPi STAT; $_{\text {PEEPi: intrinsic }}$

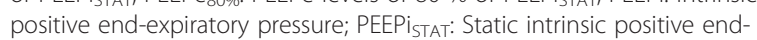
expiratory pressure; Pes: esophageal pressure; Pga: gastric pressure; $\mathrm{P}_{\mathrm{L}}$ : transpulmonary pressure; $\mathrm{PS}_{\mathrm{N}}$ : neurally triggered and cycled-off pressure support; PSp: pneumatically triggered and cycled-off pressure support; PTPеsтот: total inspiratory pressure time product per minute for esophageal pressure; PTPESTRIG: pre-trigger pressure time product per minute for

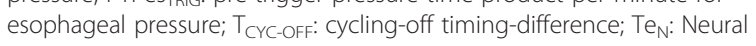
expiratory time; $T e_{\mathrm{p}}$ : ventilator (pneumatic) expiratory time; $\mathrm{Ti} / \mathrm{Tt}_{\mathrm{N}}$ : neural duty cycle; $\mathrm{Ti}_{\mathrm{N}}$ : neural inspiratory time; $\mathrm{Ti}_{\mathrm{p}}$ : ventilator (pneumatic) inspiratory time; $\mathrm{Tt}_{\mathrm{N}}$ : neural respiratory cycle time; $\mathrm{T}_{\mathrm{TRI}}$ : EAdi-to-trigger time difference; WC: volume control ventilation; $V_{T}$ : tidal volume; $\Delta \overline{\mathrm{P}}$ еsтот: total inspiratory mean deflection for esophageal pressure; $\Delta \bar{P}$ es TRIG: $_{\text {pre-trigger mean }}$ deflection of esophageal pressure; $\Delta \overline{\mathrm{P}}_{\text {LTOT: }}$ total inspiratory mean deflection for transpulmonary pressure.

\section{Competing interests}

JB and CS have been reimbursed by Maquet Critical Care (Solna, Sweden) for attending several conferences; JB and CS have participated as a speaker in scientific meetings or courses organized and financed by Maquet Critical Care; JB and CS, through Neurovent Research, serve as consultants to Maquet Critical Care. The following disclosure was agreed upon by University of Toronto, Sunnybrook Health Sciences Centre, St-Michael's Hospital and the REBs of Sunnybrook and St-Michael's to resolve conflicts of interest: Drs. Beck and Sinderby have made inventions related to neural control of mechanical ventilation that are patented. The patents are assigned to the academic institution(s) where inventions were made. The license for these patents belongs to Maquet Critical Care. Future commercial uses of this technology may provide financial benefit to Drs Beck and Sinderby through royalties. Drs Beck and Sinderby each own $50 \%$ of Neurovent Research Inc (NVR). NVR is a research and development company that builds the equipment and catheters for research studies. NVR has a consulting agreement with 
Maquet Critical Care. St-Michael's Hospital has a research agreement with Maquet Critical Care AB (Solna, Sweden) and receives royalty and overhead from this agreement. Paolo Navalesi contributed to the development of a new interface (neither used or mentioned in the present work), whose license for patent belongs to Intersurgical S.p.A., and receives royalties for that invention. His research laboratory has received equipment and grants from Maquet Critical Care and Intersurgical S.p.A. He also received honoraria/speaking fees from Maquet Critical Care, Breas, Covidien AG, and Linde AG. The remaining authors have no competing interests to declare.

\section{Authors' contributions}

LL was responsible for conception and design of the study, acquisition, analysis and interpretation of data, and drafting and revising the article for final approval of the version to be published. FX was responsible for design of study, acquisition and analysis of data, and revising the article. YY participated in the design of the study, acquisition and analysis of data, and revising the article for final approval of the version to be published. JB participated in the data analysis, interpretation of the results, and writing of the article. CS participated in the data analysis, interpretation of the results, and writing of the article. PN participated in the data analysis, interpretation of the results and writing of the article. FL participated in the data analysis, interpretation of the results, and writing of the article. HQ was responsible for the conception and design of the study, analysis and interpretation of data, drafting and revising the article for important intellectual content and final approval of the version to be published. All authors read and approved the manuscript.

\section{Acknowledgements}

We are indebted to Mr Norman Comtois for technical assistance and data analysis. This study was supported by the Natural Science Foundation of Jiangsu Province (Project BK20131302), foundation of National key Clinical Department of critical care medicine (2010), The Ministry of Health of P.R. China (Special Fund for Health-scientific Research in the Public Interest Program 201202011), and Clinical Science and Technology Specific Projects of Jiangsu Province (BL2013030). Christer Sinderby was supported by the RS McLaughlin Foundation.

\section{Author details}

'Department of Critical Care Medicine, Nanjing Zhongda Hospital, Southeast University, School of Medicine, 87 Dingjiagiao Street, Nanjing 210009, China. ${ }^{2}$ Department of Translational Medicine, Eastern Piedmont University "A. Avogadro", Novara, Italy. ${ }^{3}$ Anaesthesia and Intensive Care, Sant'Andrea Hospital, ASL VC, Vercelli, Italy. ${ }^{4}$ CRRF Mons. L. Novarese, Moncrivello, VC, Italy. ${ }^{5}$ Keenan Research Centre for Biomedical Science and Li Ka Shing Knowledge Institute of St. Michael's Hospital, Toronto, Canada. ${ }^{6}$ Department of Pediatrics, University of Toronto, Toronto, Ontario M5G 1X8, Canada. ${ }^{7}$ Department of Medicine, University of Toronto, Toronto, Ontario, Canada. ${ }^{8}$ Institute for Biomedical Engineering and Science Technology (iBEST) at Ryerson University and St-Michael's Hospital, Toronto, Canada.

\section{Received: 12 January 2015 Accepted: 1 June 2015}

\section{Published online: 09 June 2015}

\section{References}

1. Marini JJ. Dynamic hyperinflation and auto-positive end-expiratory pressure: lessons learned over 30 years. Am J Respir Crit Care Med. 2011;184:756-62.

2. Laghi F, Goyal A. Auto-PEEP in respiratory failure. Minerva Anestesiol. 2012;78:201-21.

3. Smith TC, Marini JJ. Impact of PEEP on lung mechanics and work of breathing in severe airflow obstruction. J Appl Physiol (1985). 1988;65:1488-99.

4. Petrof BJ, Legaré M, Goldberg P, Milic-Emili J, Gottfried SB. Continuous positive airway pressure reduces work of breathing and dyspnea during weaning from mechanical ventilation in severe chronic obstructive pulmonary disease. Am Rev Respir Dis. 1990;141:281-9.

5. Maclntyre NR, Cheng KC, McConnell R. Applied PEEP during pressure support reduces the inspiratory threshold load of intrinsic PEEP. Chest. 1997;111:188-93.

6. Chiumello D, Polli F, Tallarini F, Chierichetti M, Motta G, Azzari S, et al. Effect of different cycling-off criteria and positive end-expiratory pressure during pressure support ventilation in patients with chronic obstructive pulmonary disease. Crit Care Med. 2007;35:2547-52.
7. Tassaux D, Gainnier M, Battisti A, Jolliet P. Impact of expiratory trigger setting on delayed cycling and inspiratory muscle workload. Am J Respir Crit Care Med. 2005;172:1283-9.

8. Colombo D, Cammarota G, Bergamaschi V, De Lucia M, Corte FD, Navalesi $P$. Physiologic response to varying levels of pressure support and neurally adjusted ventilatory assist in patients with acute respiratory failure. Intensive Care Med. 2008;34:2010-8.

9. Spahija J, de Marchie M, Albert M, Bellemare P, Delisle S, Beck J, et al. Patient-ventilator interaction during pressure support ventilation and neurally adjusted ventilatory assist. Crit Care Med. 2010;38:518-26.

10. Bellani G, Coppadoro A, Patroniti N, et al. Clinical assessment of autopositive End-expiratory pressure by diaphragmatic electrical activity during pressure support and neurally adjusted ventilatory assist. Anesthesiology. 2014:121:563-71.

11. Sinderby C, Liu S, Colombo D, Camarotta G, Slutsky AS, Navalesi P, et al. An automated and standardized neural index to quantify patient-ventilator interaction. Crit Care. 2013;17:R239.

12. Appendini L, Patessio A, Zanaboni S, et al. Physiologic effects of positive endexpiratory pressure and mask pressure support during exacerbations of chronic obstructive pulmonary disease. Am J Respir Crit Care Med. 1994;149:1069-76.

13. Rossi A, Brandolese R, Milic-Emili J, et al. The role of PEEP in patients with chronic obstructive pulmonary disease during assisted ventilation. Eur Respir J. 1990;3:818-22.

14. Nava S, Bruschi C, Rubini F, Palo A, lotti G, Braschi A. Respiratory response and inspiratory effort during pressure support ventilation in COPD patients. Intensive Care Med. 1995;21:871-9.

15. Sydow M, Golisch W, Buscher H, Zinserling J, Crozier TA, Burchardi H. Effect of low-level PEEP on inspiratory work of breathing in intubated patients, both with healthy lungs and with COPD. Intensive Care Med. 1995;21:887-95.

16. Guerin C, Milic-Emili J, Fournier G. Effect of PEEP on work of breathing in mechanically ventilated COPD patients. Intensive Care Med. 2000;26:1207-14.

17. Yamada Y, Du HL. Analysis of the mechanisms of expiratory asynchrony in pressure support ventilation: a mathematical approach. J Appl Physiol. 2000;88:2143-50.

18. Colombo D, Cammarota G, Alemani M, Carenzo L, Barra FL, Vaschetto R, et al. Efficacy of ventilator waveforms observation in detecting patientventilator asynchrony. Crit Care Med. 2011;39:2452-7.

19. Thille AW, Cabello B, Galia F, Lyazidi A, Brochard L. Reduction of patientventilator asynchrony by reducing tidal volume during pressure-support ventilation. Intensive Care Med. 2008;34:1477-86.

20. Thille AW, Rodriguez P, Cabello B, Lellouche F, Brochard L. Patient-ventilator asynchrony during assisted mechanical ventilation. Intensive Care Med. 2006:32:1515-22

21. Chao DC, Scheinhorn DJ, Stearn-Hassenpflug M. Patient-ventilator trigger asynchrony in prolonged mechanical ventilation. Chest. 1997;112:1592-9.

22. Beck J, Sinderby C, Lindström L, Grassino A. Effects of lung volume on diaphragm EMG signal strength during voluntary contractions. J Appl Physiol. 1998:85:1123-34.

23. Guerin C, Fournier G, Milic-Emili J. Effects of PEEP on inspiratory resistance in mechanically ventilated COPD patients. Eur Respir J. 2001;18:491-8.

24. Caramez MP, Borges JB, Tucci MR, Okamoto VN, Carvalho CR, Kacmarek RM, et al. Paradoxical responses to positive end-expiratory pressure in patients with airway obstruction during controlled ventilation. Crit Care Med. 2005;33:1519-28

25. Brander L, Leong-Poi H, Beck J, Brunet F, Hutchison SJ, Slutsky AS, et al. Titration and implementation of neurally adjusted ventilatory assist in critically ill patients. Chest. 2009;135:695-703.

26. Patroniti N, Bellani G, Saccavino E, Zanella A, Grasselli G, Isgrò S, et al. Respiratory pattern during neurally adjusted ventilatory assist in acute respiratory failure patients. Intensive Care Med. 2012;38:230-9.

27. Grasselli G, Beck J, Mirabella L, Pesenti A, Slutsky AS, Sinderby C. Assessment of patient-ventilator breath contribution during neurally adjusted ventilatory assist. Intensive Care Med. 2012;38:1224-32.

28. Zakynthinos SG, Vassilakopoulos T, Zakynthinos E, Mavrommatis A, Roussos C. Contribution of expiratory muscle pressure to dynamic intrinsic positive end-expiratory pressure: validation using the Campbell diagram. Am J Respir Crit Care Med. 2000;162:1633-40.

29. Lessard MR, Lofaso F, Brochard L. Expiratory muscle activity increases intrinsic positive end-expiratory pressure independently of dynamic hyperinflation in mechanically ventilated patients. Am J Respir Crit Care Med. 1995;151:562-9. 
30. Yan S, Kayser B, Tobiasz M, Sliwinski P. Comparison of static and dynamic intrinsic positive end-expiratory pressure using the Campbell diagram. Am J Respir Crit Care Med. 1996;154:938-44.

31. Ranieri VM, Mascia L, Petruzzelli V, Bruno F, Brienza A, Giuliani R. Inspiratory effort and measurement of dynamic intrinsic PEEP in COPD patients: effects of ventilator triggering systems. Intensive Care Med. 1995;21:896-903.

32. Maltais F, Reissmann H, Navalesi P, Hernandez P, Gursahaney A, Ranieri VM, et al. Comparison of static and dynamic measurements of intrinsic PEEP in mechanically ventilated patients. Am J Respir Crit Care Med. 1994;150:1318-24.

\section{Submit your next manuscript to BioMed Central} and take full advantage of:

- Convenient online submission

- Thorough peer review

- No space constraints or color figure charges

- Immediate publication on acceptance

- Inclusion in PubMed, CAS, Scopus and Google Scholar

- Research which is freely available for redistribution 